Canadian

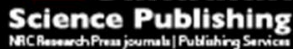

Canadian Geotechnical Journal Revue canadienne de géotechnique

\title{
Lateral response of piles in weak calcareous sandstone
}

\begin{tabular}{|r|l|}
\hline Journal: & Canadian Geotechnical Journal \\
\hline Manuscript ID & cgj-2015-0600.R1 \\
\hline Manuscript Type: & Article \\
\hline Date Submitted by the Author: & 21 -Apr-2016 \\
\hline Keyword: & pile, Lateral loading, weak rock, Field test \\
\hline & $\begin{array}{l}\text { Guo, Fengju; The University of Western Australia } \\
\text { \& Mining Engineering }\end{array}$ \\
\hline
\end{tabular}

\section{SCHOLARONE"}

Manuscripts 
Lateral response of piles in weak calcareous sandstone

\author{
F. Guo ${ }^{1} \mathrm{BE}$
}

B.M. Lehane ${ }^{2}$ BE, MAI, DIC, PhD, FIEAust, CPEng

${ }^{1}$ PhD student

School of Civil \& Resource Engineering

The University of Western Australia.

35 Stirling Highway, Crawley WA 6009, Australia

${ }^{2}$ Corresponding Author

Professor, School of Civil, Environmental \& Mining Engineering

The University of Western Australia.

35 Stirling Highway, Crawley WA 6009, Australia

Phone +61864882417

Fax $\quad+61864881044$

E-mail: Barry.Lehane@uwa.edu.au 


\begin{abstract}
Existing design methods for laterally loaded piles in soft rock have insufficient supporting case history data and consequently cannot be regarded as having a high level of reliability. This paper addresses the shortage of experimental data by describing the results from four instrumented lateral load tests on drilled and grouted piles installed in weak calcareous sandstone. The derived lateral load transfer $(p-y)$ curves are first compared with existing approaches for weak rock and cemented soils. The paper then examines the potential of using CPT data directly for the design analysis of laterally loaded piles in weak rock. It is shown that equivalent elastic moduli of the rock controlling values of $q_{c}$ at the test site are very similar to those controlling lateral pile response. This finding is used to formulate a simple bi-linear $p-y$ approximation of the lateral response that requires $q_{c}$ data and an estimate of the rock's effective stress strength parameters. It is shown that such an approach is likely to be sufficient for many practical purposes if the moment capacity of the pile section is incorporated in the analysis.
\end{abstract}

\title{
Keywords:
}

Pile; Lateral loading; Pile; Weak rock; Field Test 


\section{Introduction}

Documented experiments investigating the response to lateral load of piles in rock are extremely rare. Given the shortage of available guidance, Reese (1997) sought to provide recommendations for practitioners but could only uncover the lateral pile tests reported by Nyman (1980) and Speer (unpublished 1992) to support his proposed load transfer $p-y$ formulation. Reese et al. (2010) proposed the same formulation for rock without any additional supporting case history data and suggest that it should only be used with caution given the meager amount of data on which it is based. Moreover, the formulation assumes that the rock can be sampled to obtain a representative measure of the unconfined compressive strength and that cores exist from which an estimate of the rock quality designation (RQD) or fracture spacing can be established. The approach is therefore not suitable for very weak or highly fractured rocks for which core recovery is often very poor.

While the weak rock approach of Reese (1997) has been incorporated into many of the commercially available computer codes and has widespread use, other formulations have also been suggested. These include the continuum approach suitable for strong rocks proposed by Carter and Kulhawy (1992), and the load transfer approaches reported by Abbs (1983), Erbrich (2004) and Reese et al. (2010). Abbs (1983) attempted to capture the brittle nature of weak carbonate rocks, assuming that the pre-peak response could be simulated using a stiff clay model and the ultimate (residual) lateral resistance approached that of a loose sand. Erbrich (2004) developed another $p-y$ approach for carbonate rocks which specifically allowed for the progressive 'chipping' of rock wedges close to the surface as lateral loads increased. Reese and Van Impe (2001) developed the method proposed by Evans and Duncan (1982) for cemented soils using a load transfer curve similar to that of sand but adjusted for the additional lateral resistance arising from cementation (the $c^{\prime}$ component of strength).

All existing methods for analysing laterally loaded piles in cemented soils and weak rock 
have insufficient supporting case history data and consequently cannot be regarded as having a high level of reliability. This paper addresses the shortage of experimental data by describing the results from lateral load tests conducted on four instrumented drilled and grouted piles installed in weak calcareous sandstone. A drilled and grouted pile, which is essentially equivalent to a drilled shaft or bored pile, is the preferred pile type in many offshore environments where the carbonate content of the soil is high.

The derivation of $p-y$ curves from the test pile responses is presented and shown to require careful interpretation of the structural response of the piles. These curves are first compared with those estimated using existing approaches and with the available laboratory data. As the weak rock at the test site could not be cored satisfactorily (although block samples were attained), attention is focused on establishing a general basis for how $p$ - $y$ curves for cemented soils and weak rocks can be related to the Cone Penetration Test (CPT) end resistance $\left(q_{c}\right)$. A simple bi-linear $p-y$ approximation of the lateral response that requires $\mathrm{q}_{\mathrm{c}}$ data and an estimate of the rock's effective stress strength parameters is subsequently proposed.

\section{Site and Soil Characterization}

The site of the lateral pile tests was a limestone quarry in Pinjar, which is about $25 \mathrm{~km}$ north of Perth, Western Australia. The rock is mined as a "medium grade limestone" and is part of the Tamala Limestone formation. This formation comprises calcarenite and/or calcareous cemented, fine to very coarse, well graded sand that originated from wind-blown sediment and accumulated as coastal sand dunes during the Pleistocene era, and later lithified when the lime content dissolved to cement the grains together (Playford et al. 1976).

A test pit excavated at the site indicated that, as seen in Fig. 1, the deposit is characterized by distinct large-scale horizontal bedding with cemented band thicknesses varying from about 5 to $40 \mathrm{~mm}$ (typically about $25 \mathrm{~mm}$ ) interlayered with discontinuous very poorly cemented 
bands 2 to $10 \mathrm{~mm}$ in thickness. The carbonate and silica content of sampled materials were typically $40 \pm 25 \%$ and $60 \pm 25 \%$ respectively, indicating that the general deposit classifies as calcareous sandstone according to the Clark and Walker (1977) classification system. The in-situ water content is typically $4 \%$ and the degree of saturation is about $20 \%$. In-situ sand cone replacement tests indicated a unit weight of $15.8 \pm 0.2 \mathrm{kN} / \mathrm{m}^{3}$. The average grain size is 0.3 to $0.4 \mathrm{~mm}$ (measured after grinding the cemented materials using a mortar and pestle). The average point load indices $\left(I_{s, 50}\right)$ of the cemented materials tested in the vertical and horizontal direction were $0.26 \mathrm{MPa}$ and $0.15 \mathrm{MPa}$ respectively, but measurements of these indices showed a relatively large coefficient of variation of 0.7 .

A total of six cone penetration tests (CPTs) and eight seismic cone penetration tests (SCPTs) were performed within $8 \mathrm{~m}$ of the test piles. The range and average of the end resistances $\left(q_{c}\right)$ and friction ratios recorded are shown on Fig. 2. Friction ratios were consistently within the range $0.4 \%$ to $0.6 \%$ while $q_{c}$ values between 1 and $2 \mathrm{~m}$ depth (i.e., approximately three pile diameters in the zone most critical for the lateral load tests) were typically $35 \pm 15 \mathrm{MPa}$. The traces show no clear evidence of the bedded and cemented nature of the deposit observed in the test pits (as seen in Fig. 1) and, without such knowledge, standard CPT soil behavior type charts (e.g., Robertson 2009) suggest the material is an overconsolidated very dense sand. The SCPT shear wave velocities $\left(V_{s}\right)$ do, however, reveal the cemented nature of the deposit and are typically in the range $520 \mathrm{~m} / \mathrm{s}$ to $1450 \mathrm{~m} / \mathrm{s}$ with an average value of $950 \mathrm{~m} / \mathrm{s}$. These $V_{s}$ values correspond to small strain shear moduli $\left(G_{0}\right)$ shown on Fig. 2 with typical values of $1.4 \pm 0.7$ $\mathrm{GPa}$ in the area of interest for the lateral pile tests.

Direct shear tests were performed at a drained rate of displacement on 'chunks' or pieces of the material in a $60 \times 60 \mathrm{~mm}$ shear box. These pieces, where were typically about 20-30 $\mathrm{mm}$ high and 40 to $50 \mathrm{~mm}$ long and wide, were fixed to the internal wall of the shear box with plaster using the technique described by Goodman (1989), and others. Strips of Teflon were 
positioned at the interface between the plaster in the upper and lower boxes. Other shear box tests were performed on loose samples of reconstituted sand (achieved by grinding the cemented materials). The area of the sample on shearing plane was determined on the completion of each test and was typically about $60 \%$ of the full plan area of the shear box.

The peak shear stresses recorded in the direct shear tests are summarized on Fig. 3. The reconstituted samples indicated an ultimate (or critical state) friction angle $\left(\phi_{\mathrm{cs}}^{\prime}\right)$ of about $40^{\circ}$; this angle is typical of angular coarse grained deposits with a high percentage of carbonates (e.g. Lehane et al. 2012). The intact samples show distinct evidence of a $c^{\prime}$ component of strength, where $c^{\prime}$ lies between $180 \mathrm{kPa}$ and $300 \mathrm{kPa}$. All of these intact samples display a marked reduction in the shear stress that could be sustained following attainment of the peak values at a relative displacement of about $2 \mathrm{~mm}$. Additional tests were performed under fully saturated conditions on intact samples (see Fig. 3) and these revealed comparable $c^{\prime}$ values to the other rock samples (tested with no water in the shear box bath) indicating that observed $c^{\prime}$ is not related to suction in the intact materials.

Drained triaxial tests on carefully carved, vertically orientated, (near) cylindrical samples of the deposit were also performed after saturation and isotropic consolidation to consolidation stresses $\left(\sigma_{3}^{\prime}\right)$ of 50,100 and $200 \mathrm{kPa}$. The deviator stress $(\mathrm{q})$-axial strain $\left(\varepsilon_{\mathrm{a}}\right)$ relationships recorded are plotted on Fig. 4a. It is evident that, for each of the three samples, deviator stresses develop peak values of between about 1.5 and $1.75 \mathrm{MPa}$ at axial strains of $1 \pm 0.5 \%$ but these reduce significantly as axial straining progresses and cementation bonds are broken. The Young's moduli, defined at $50 \%$ of the peak strength, vary between $230 \mathrm{MPa}$ and $320 \mathrm{MPa}$.

The stresses recorded at peak conditions are plotted in terms of the stress invariants $t_{\mathrm{f}}$ and $\mathrm{s}_{\mathrm{f}}$ on Fig. $4 \mathrm{~b}$ (where $t_{\mathrm{f}}$ and $s_{\mathrm{f}}$ are as defined on the figure and $\sigma_{1 \mathrm{f}}^{\prime}$ and $\sigma_{3 \mathrm{f}}^{\prime}$ are the major and minor principal effective stresses at peak), where they are compared with the strength envelope deduced from the shear box tests on Fig. 3. It is seen that the results for the (larger) triaxial 
specimens are in general agreement with shear box data but plot at the lower end of this envelope range.

If the Mohr-Coulomb failure criterion is assumed, the unconfined compressive strength $\left(q_{\mathrm{u}}\right)$ of the triaxial samples can be estimated from:

[1] $\quad q_{u}=2 c^{\prime} \tan \left(45+\frac{\varphi^{\prime}}{2}\right)$

Assuming $c^{\prime}$ and $\phi^{\prime}$ values of $180 \mathrm{kPa}$ and $40^{\circ}$, as indicated in Fig. 4b, Eq. [1] implies unconfined compressive strength for vertical loading of between 1 and 1.7 MPa. This range is consistent with the average value of $1.1 \mathrm{MPa}$ and standard deviation of $0.8 \mathrm{MPa}$ indicated in 13 unconfined compressive strength tests on vertically orientated, carved prismatic block samples (Guo 2015). The corresponding mean ratio of $q_{\mathrm{u}}$ to the point load index $I_{s, 50}$ value (with an average value of $0.26 \mathrm{MPa}$ ) is approximately 4 to 5 and a little less than a (typical) value of 7 , quoted by Look (2014), and others, for rocks of this nature.

\section{Experimental Details}

Two $340 \mathrm{~mm}$ diameter and two $450 \mathrm{~mm}$ diameter, $5 \mathrm{~m}$ long, drilled and grouted test piles were constructed at Pinjar, using the continuous flight auger method. Full length steel pipes with a yield stress of $350 \mathrm{MPa}$ were inserted in the grouted holes after removal of the auger. Steel pipes with a diameter of $219 \mathrm{~mm}$ and wall thickness of $4.8 \mathrm{~mm}$ were installed in the 340 $\mathrm{mm}$ piles while $356 \mathrm{~mm}$ diameter pipes with a wall thickness $6.4 \mathrm{~mm}$ were used for the 450 $\mathrm{mm}$ diameter piles. Each test pile was instrumented with 6 levels of strain gauges located on the tension and compression outer faces of the steel pipes. A plastic inclinometer access tube was inserted along the centerline of each pile.

The testing details are summarized in Table 1 and illustrated on Fig. 5. These involved jacking apart the two $340 \mathrm{~mm}$ diameter piles followed by jacking apart the two $450 \mathrm{~mm}$ 
diameter piles. The respective locations of the 340mm piles (denoted, P340A and P340B) and 450mm piles (denoted, P450A and P450B) are shown in Fig. 5a. A $1 \mathrm{~m}$ deep pit, measuring $5 \mathrm{~m} \times 8 \mathrm{~m}$, was excavated in the area of the test piles to facilitate application of the lateral loads and to avoid the influence on the test results of the upper (more variable) $1 \mathrm{~m}$ of the deposit. CPTs performed after lateral extension of the pit when the pile tests were completed indicated closely comparable $\mathrm{q}_{\mathrm{c}}$ values to those shown in Fig. 2, apart from in the upper 0.1 to $0.15 \mathrm{~m}$ before the cone reached a deep penetration mode.

The testing program initially involved application of a relatively small lateral load at $0.1 \mathrm{~m}$ below the head of each pile and about $0.9 \mathrm{~m}$ above the pit level, i.e., load eccentricity $e=0.9$ $\mathrm{m}$. The primary purpose of this phase of the testing was to provide on-site calibration of the moment-strain relationship at the strain gauge levels located above the base of the pit (i.e. at negative $z$ values; see Fig. 5b). The initial lateral load applied to P340A and P340B was 40 $\mathrm{kN}$, which on removal gave permanent lateral displacements of about $1.4 \mathrm{~mm}$ at the pile head and less than $0.2 \mathrm{~mm}$ at ground level. The initial load applied to P450A and P450B was 140 $\mathrm{kN}$ and this led to permanent displacements of similar magnitude. Large scale cracks appeared in the grout annulus outside of the steel pipes during this testing phase indicating that this annulus made a negligible contribution to the piles' bending stiffness.

The outer grout was removed from the exposed sections of the piles and the lateral load eccentricity was reduced to approximately $0.32 \mathrm{~m}$ for the $340 \mathrm{~mm}$ piles and $0.20 \mathrm{~m}$ for the $450 \mathrm{~mm}$ piles. The flexural rigidities of the above ground sections of the $340 \mathrm{~mm}$ and $450 \mathrm{~mm}$ piles at this stage of loading was assessed from the preceding calibration exercise to be 4300 $\mathrm{kNm}^{2}$ and $25300 \mathrm{kNm}^{2}$ respectively. Loading was applied incrementally with 10 minute waiting periods between each $10 \mathrm{kN}$ load increment for the $340 \mathrm{~mm}$ piles and $20 \mathrm{kN}$ load increment for the $450 \mathrm{~mm}$ piles. 


\section{Experimental Results}

The variations of lateral pile head load $H$ with lateral displacement, $y_{h}$ (recorded at the level of applied load) when the point of load application was $0.26 \pm 0.06 \mathrm{~m}$ above ground level are shown on Fig. 6 (noting that the maximum lateral load that could be applied was limited by the lower capacity pile in each pair). It is evident that piles P340B and P450B (both on the same side of the pit; see Fig. 5a) had lower capacities than their counterparts and begin to exhibit significant yielding once $y_{h}$ reached between about $4 \mathrm{~mm}$ and $7 \mathrm{~mm}$. Extrapolation of the $H-y_{h}$ data for P450A suggests that this pile had an ultimate capacity about $50 \mathrm{kN}$ greater than the ultimate value of $480 \mathrm{kN}$ sustained by P450B. The observed capacity of P340B of $155 \mathrm{kN}$ is noticeably less than that of $\mathrm{P} 340 \mathrm{~A}$ which only experienced a permanent displacement of $2.2 \mathrm{~mm}$ on unloading from $155 \mathrm{kN}$.

Displacement profiles derived from inclinometer measurements obtained during testing of P340A and P340B are shown on Fig. 7. Unfortunately no such data were obtained for the $450 \mathrm{~mm}$ diameter piles as the inclinometer access tube melted due to high curing temperatures (on discovery, the melting point of the PVC tubes was found to be only $85^{\circ} \mathrm{C}$ ). The data on Fig. 7 indicate that virtually no pile movement occurs below a depth of $1 \mathrm{~m}$ (or 3 pile diameters) and that the rock properties below this depth had no significant impact on the pile performance. The displacement profiles also indicate that the ultimate pile capacity was controlled by the structural capacity of the pile section and not by a geotechnical failure (for which rotation would take place close to the pile toe).

The derivation of net lateral stresses acting on the test piles requires accurate estimation of the bending moments in the piles and these moments were assessed using the moment-curvature relationship derived using the on-site calibration exercise referred to above. The results from this exercise are presented on Fig. 8 which plots the curvatures $(\kappa)$ measured at each (above ground) strain gauge location for given applied moments $(M)$; the curvature at 
any given level was determined as the difference in strain recorded by the gauges on the compression and tension faces of the respective steel pipes divided by the pipe diameter; $M$ was simply derived as the product of the applied load and the distance of this load from the strain gauge level. Reasonable agreement in the inferred $M$ - $\kappa$ relationships was obtained, noting that some of the gauges would lead to the inference of a slightly lower $M-\kappa$ slope as they were marginally below ground level. These on-site calibrations provided the base data from which results could be extrapolated.

The computer program Oasys ADSEC (Oasys 2013) was used to extrapolate the measured $M-\kappa$ relationships to large curvature levels and ultimate conditions. ADSEC is a program for determination of the bending characteristics of structural cross-sections and requires specification of the non-linear stress-strain properties (in tension and compression) of the materials within any particular cross-section; the geometries of the $340 \mathrm{~mm}$ and $450 \mathrm{~mm}$ cross-sections are provided in Table 1. The (un-factored) parabolic compression-strain curve with the form provided in the European structural engineering standard (EuroCode 2) was employed for the grout and the corresponding stress strain curve for the Grade $350 \mathrm{MPa}$ steel tubes was used. Best fit average secant grout Young's moduli matching the on-site measurement of the moment-curvature relationships were lower than anticipated and approximately $4 \mathrm{GPa}$ for both the $340 \mathrm{~mm}$ and $450 \mathrm{~mm}$ diameter piles. The compressive and tensile strengths adopted for the grout were $12 \mathrm{MPa}$ and 1.5 MPa respectively and these are seen on Fig. 8 to provide a reasonable representation of the sections' bending capacities; the onset of significant yielding was calculated to occur at respective moments $\left(M_{y}\right)$ of $67 \mathrm{kNm}$ and $228 \mathrm{kNm}$ for the $340 \mathrm{~mm}$ and $450 \mathrm{~mm}$ diameter piles.

The bending moments induced at the strain gauge levels of each test pile were derived using the $M-\kappa$ relationships on Fig. 8. Best estimate moment profiles with depth $(z)$ were then fitted to these data using the following relationship form (where $a_{i}, \mathrm{i}=0$ to $n$ are empirical fitting 
coefficients):

$$
M=\left(1-\frac{1}{e^{a_{0} z}+1}\right) \sum_{i=1}^{n} a_{i} z^{i-1}
$$

These best-fit moment profiles are shown together with the estimated $M$ data on Fig. 9. The net stress per meter run $(p)$ and net pressure $(P=p / \mathrm{D})$ on each pile at any depth, $z$, were then obtained by double differentiation of Eq. [2]. The displacements (y) at the corresponding depth and level of applied load were determined from Fig. 7 for the $340 \mathrm{~mm}$ diameter piles. No displacement data were available for the $450 \mathrm{~mm}$ piles but the moment profiles together with the $H-\delta_{h}$ trend for these piles could be used to obtain a reasonable estimate of the ultimate lateral net pressures $\left(P_{u}\right)$. Displacements could not be estimated with accuracy from double integration of Eq. [2] due to the non-linear pile flexural rigidity coupled with the imprecise nature of the $M$ profiles.

The net pressure (P) - displacement (y) curves that could be deduced with confidence (i.e. when lateral displacements measurements were deemed sufficiently accurate) for the $340 \mathrm{~mm}$ diameter piles are shown on Fig. 10. As may be expected from the load-displacement response shown on Fig. 6, the $P-y$ curves for P340A are stiffer than those of P340B. Peak (or ultimate) pressures $\left(P_{u}\right)$ developed on both piles at a displacement of about $0.5 \pm 0.1 \%$ of the pile diameter $(D)$ and generally ranged from $1.3 \mathrm{MPa}$ to $2.5 \mathrm{MPa}$. It is also evident that the P-y responses show inconsistent trends with the relative depth $(\mathrm{z} / \mathrm{D})$ and no clear tendency for ultimate/maximum pressures to increase with $\mathrm{z} / \mathrm{D}$ over the (limited) range investigated. More brittleness is in evidence for P340A (which developed higher pressures) but, in general, the level of brittleness is relatively mild compared to that observed in the triaxial tests (Fig. 4). 


\section{Discussion}

\section{Ultimate lateral pressures}

The net stresses for the $450 \mathrm{~mm}$ diameter piles were derived from the pile bending moments but extrapolation of these to peak lateral pressures was more approximate because of the absence of inclinometer data; the lateral movements at depth used for this extrapolation were assessed using the pile head displacement data (see Fig. 6). These piles displayed significant signs of yielding when the applied lateral load was $480 \mathrm{kN}$; the maximum moment in the piles at this stage was about $250 \mathrm{kNm}$ and occurred at a depth between $0.4 \mathrm{~m}$ and $0.5 \mathrm{~m}$ (equivalent to one diameter).

The estimated maximum pressures $\left(P_{u}\right)$ for the $340 \mathrm{~mm}$ and $450 \mathrm{~mm}$ piles are plotted on Fig. 11 and have a mean and standard deviation of $2 \mathrm{MPa}$ and $0.7 \mathrm{MPa}$ respectively. It is evident that $P_{u}$ does not vary systematically with z/D. The coefficient of variation of $P_{u}$ is broadly compatible with that of the CPT $\mathrm{q}_{\mathrm{c}}$ data shown on Fig. 2.

These $P_{u}$ values are compared on the same figure with predictions obtained using the Reese (1997) formulation for weak rock and the Brinch-Hansen (1961) and Reese and Van Impe (2001) formulations for cemented $\left(c-\phi^{\prime}\right)$ soils. The calculations assumed $\phi^{\prime}=40^{\circ}$ and adopted the best fit $c^{\prime}$ value of $180 \mathrm{kPa}$ seen in the triaxial tests (Fig. 4), which is equivalent to the lowerbound $c^{\prime}$ value obtained in shear box tests (Fig. 3).

Brinch-Hansen (1961) predicts $P_{u}$ as a function of $c^{\prime}$ and $\phi^{\prime}$ using the following expression:

$$
P_{u}=K_{q} \sigma^{\prime}+K_{c} c^{\prime}
$$

Where $K_{\mathrm{q}}$ and $K_{\mathrm{c}}$ are passive resistance coefficients and prescribed functions of $c^{\prime}, \varphi^{\prime}$ and normalised depths $(z / D)$ and can be found in Brinch-Hansen (1961) and textbooks such as 
Tomlinson and Woodward (2007). The Reese (1997) formulation relates $P_{u}$ with the unconfined compressive strength $\left(q_{u}\right)$ as:

[4a] $\quad P_{u}=\alpha q_{u}\left(1+1.4 \frac{z}{D}\right) ; \quad z / D \leq 3$

[4b] $\quad P_{u}=5.2 \alpha q_{u} ; z / D>3$

Where $\alpha=$ strength reduction factor $=1.0$ (assumed in this study) and, in the absence of $q_{u}$ data, $q_{u}$ can be approximated from $c^{\prime}$ and $\phi^{\prime}$ using Eq. [1].

Using a concept initially proposed by Evans and Duncan (1982), Reese and Van Impe (2001) represent the ultimate resistance as the sum of the cementation/ cohesive component $\left(P_{u c}\right)$ and frictional component $\left(P_{u \varphi}\right)$, where the latter is multiplied by an empirical adjustment factor $(A)$, i.e.

[5] $P_{u}=A P_{u \phi}+P_{u c}$

The comparisons on Fig. 10 reveal some significant differences between estimates made using Eqs. [3], [4] and [5]. The Brinch Hansen (1961) predictions for ultimate pressures are evidently non-conservative for the Pinjar material whereas those obtained using the Reese and Van Impe (2001) formulation are significant under-estimates at shallow depths. The Reese (1997) formulation with $\alpha=1$ gives pressures that are in better agreement but are at the lower end of the range of measured resistances. All methods predict a stronger dependence on $\mathrm{z} / \mathrm{D}$ than indicated by the measurements.

\section{$P-y$ response}

The $P-y$ data from both $340 \mathrm{~mm}$ diameter test piles are combined in Fig. 12, which shows bi-linear (linear-elastic perfectly plastic) approximations to the curves for average, lowerbound (LB) and upperbound (UB) cases. It is assumed for the purposes of this plot that 
these respective cases correspond to the in-situ mean, lowerbound and upperbound CPT $\mathrm{q}_{\mathrm{c}}$ values of $35 \mathrm{MPa}, 20 \mathrm{MPa}$ and $50 \mathrm{MPa}$; see Fig. 2. Following Poulos (1971), the ratio of $P$ to $y$ for a laterally load pile is approximately $0.8 \mathrm{E}_{\mathrm{s}} / \mathrm{D}$, where $\mathrm{E}_{\mathrm{s}}$ is the equivalent linear elastic modulus $\left(\mathrm{E}_{\mathrm{s}}\right)$ of the soil. $\mathrm{E}_{\mathrm{s}}$ moduli determined in this way are seen on Fig. 12 to be approximately 12 times the corresponding $\mathrm{q}_{\mathrm{c}}$ value for each of the average, lowerbound and upperbound cases. Maximum pressures $\left(P_{u}\right)$ are close to being developed at a lateral displacement of 1.5 to $2 \mathrm{~mm}$ or $\mathrm{y} / \mathrm{D}$ value about $0.5 \%$ and these are approximately equal to 0.045 times the CPT $q_{c}$ value at all $z / D$ values considered $(\mathrm{z} / \mathrm{D} \leq 1.5)$.

The mean measured $P-y$ trend is shown in normalized form on Fig. 13, where each P value is normalized by the maximum pressure recorded at the depth $\left(P_{u}\right)$. This trend is compared with the bounds of $P / P_{u}$ vs $y / D$ proposed for weak rock by Reese (1997) and with the recommendation for a $c^{\prime}-\varphi^{\prime}$ soil given by Reese and Van Impe (2001), assuming $c^{\prime}=180 \mathrm{kPa}$ and $\varphi^{\prime}=40^{\circ}$; see Fig. 4). It is evident that the Reese and Van Impe formulation provides a closer match to the average field curve, despite $P_{u}$ values for this method being under-predicted (see Fig. 11). The normalized curves given by the weak rock model are well above those observed in the in the field over the early stages of loading.

\section{Prediction of pile response using a CPT-based bi-linear p-y curve}

The simple bi-linear approximation to the $p$ - $y$ curves indicated on Fig. 12, assuming $E_{s} / q_{c}=12$ and $P_{u} / q_{c}=0.045$, is now examined to assess the ability of this simplification to provide reasonable predictions of the lateral response of the Pinjar piles, including the $450 \mathrm{~mm}$ dimeter piles for which $p-y$ data were not obtained. A program referred to as LAP (Doherty 2014) was used for the calculations. This program represents the pile as a series of beam elements and the soil as a series of non-linear, non-interacting $p-y$ springs located between each 
beam element; the program is identical to many commercially available laterally loaded pile programs and its accuracy was verified by a parallel series of calculations for the Pinjar piles performed by ALP (Oasys 2013), which is a very similar program but does not incorporate pile yielding.

An important element of the observed response was structural yielding of the Pinjar piles. The analyses assigned a simple bi-linear moment-curvature (M- $\kappa)$ approximation to the curves on Fig. 8, with yield moments $\left(M_{y}\right)$ assumed to be those corresponding to the onset of significant non-linearity in the M- $\kappa$ relationship. The calculated pile head load-displacement $\left(H-y_{h}\right)$ responses, which were performed for the mean, upperbound and lowerbound $q_{c}$ values are compared with the measured data on Fig. 14.

It is seen that the upper and lower bound calculations bracket the measured $H-y_{\mathrm{h}}$ data for all piles, apart from P450A. Calculations using the mean $p-y$ response (corresponding to $q_{c}=35$ $\mathrm{MPa}$ ) provide matches to the field behavior which is sufficient for most practical purposes. A more general correlation between p-y responses and CPT data is explored in the following.

\section{Correlation with $C P T q_{\mathrm{c}}$}

The assessment of in-situ stiffness and strength from weak rocks such as those at Pinjar is problematic because of the immense difficulties obtaining undisturbed core samples. Given the tendency for the $p-y$ responses to reflect CPT $q_{c}$ values and their variability (Fig. 12), a spherical cavity expansion analogy for CPT penetration is now examined to further investigate the potential of a CPT based method to predict lateral pile response in weak rocks.

The spherical expansion approach to predict $q_{c}$ has found widespread application and is described by Yu and Houlsby (1991) and applied in sands by Suryasentana and Lehane (2014) and in clays by $\mathrm{Xu}$ and Lehane (2008). The drained spherical cavity expansion limit pressure 
$\left(p_{\text {lim }}\right)$ is related to $q_{c}$ (for a cone with a $60^{\circ}$ apex angle) by the following expression proposed by Randolph et al. (1994):

$$
q_{\mathrm{c}}=p_{\text {lim }}\left(1+\tan \varphi^{\prime} \tan 60^{\circ}\right)
$$

Values of $p_{\text {lim }}$ can be estimated using the Yu and Houlsby (1991) solution for cavity expansion in a linear elastic Mohr Coulomb soil, for which the controlling parameters are the $\mathrm{c}^{\prime}$ and $\varphi^{\prime}$ values, the dilation angle $(\psi)$, the stress level (or depth) and the equivalent linear elastic modulus $\left(\mathrm{E}_{\mathrm{s}}\right)$ for the material. $\mathrm{CPT} q_{c}$ resistances using these $p_{\text {lim }}$ values and Equation (6) were calculated assuming a fixed friction angle $\left(\varphi^{\prime}\right)$ of $40^{\circ}$ (a typical value for carbonate rich soils/rocks) and a dilation angle of zero. For these calculations, combinations of $c^{\prime}$ and $E_{S}$ values were deduced that gave calculated $q_{c}$ values equal to either the lowerbound, mean or upperbound $\mathrm{q}_{\mathrm{c}}$ resistances of $20 \mathrm{MPa}, 35 \mathrm{MPa}$ and $50 \mathrm{MPa}$ measured at Pinjar. These analyses held the vertical effective stress constant at $10 \mathrm{kPa}$, which was representative of the area of interest for the Pinjar piles. Other analyses indicated that the derived c' values, which were generally in the observed ranged of $50 \mathrm{kPa}$ to $300 \mathrm{kPa}$, did not exhibit high sensitivity to the assumed stress level or to the assumption of a zero dilation angle because of the relatively high values of c' involved.

Ratios of $\mathrm{q}_{\mathrm{c}} / \mathrm{c}^{\prime}$ determined in this way are plotted on Fig. 15a against the $\mathrm{E}_{\mathrm{s}} / \mathrm{q}_{\mathrm{c}}$ ratios required to give the three target CPT $\mathrm{q}_{\mathrm{c}}$ resistances. It is evident that, for the range of $\mathrm{E}_{\mathrm{s}} / \mathrm{q}_{\mathrm{c}}$ values shown by the $340 \mathrm{~mm}$ diameter piles at Pinjar (deduced from Fig. 12), $\mathrm{q}_{\mathrm{c}} / \mathrm{c}^{\prime}$ is typically about 160 and hence c' values are approximately $125 \mathrm{kPa}, 220 \mathrm{kPa}$ and $310 \mathrm{kPa}$ for the respective lowerbound, mean and upperbound $q_{c}$ resistances of $20 \mathrm{MPa}, 35 \mathrm{MPa}$ and $50 \mathrm{MPa}$. These $\mathrm{c}^{\prime}$ values are in good agreement with the range of values inferred from shear box and triaxial tests (Figs. 3 and 4), which implies that the operational $E_{s}$ values controlling cavity expansion and cone penetration (as deduced using Yu and Houlsby, 1991) are very similar to those controlling lateral pile response. Guo (2015) also showed that specification of these 
operational $E_{s}$ values in elastic 3D Finite Element analyses of the Pinjar tests provided almost identical predictions of the $\mathrm{H}-y_{h}$ responses predicted by the LAP program in Fig. 14; this agreement provides justification for the use of the Poulos (1971) correlation between $E_{\mathrm{s}}$ and the linear elastic component of the $p-y$ curve.

Support for the estimated $q_{d} / c^{\prime}$ ratio of 160 at Pinjar is provided in Fig. 15b, which plots $q_{d} / c^{\prime}$ against the ratio of the equivalent soil/rock modulus $\left(E_{s}\right)$ to the unconfined compressive strength $\left(q_{u}\right)$, where $q_{u}$ is calculated from Eq. [1] with $\phi^{\prime}=40^{\circ}$. It is seen that $q_{c} / c^{\prime}$ is also about 160 for the mean of the $E_{s} / q_{u}$ range of 200 to 580 reported by Goodman (1989) for sandstones and limestones.

The ultimate pressures recorded on the $340 \mathrm{~mm}$ piles were approximately $0.045 \mathrm{q}_{\mathrm{c}}$ whereas higher values of $0.07 q_{c}$ were indicated by the tests on the $450 \mathrm{~mm}$ piles (which explains the under-prediction for these piles on Fig. 14b). Therefore for an average $P_{u} / q_{c}$ ratio of 0.06 and with $q_{c} / c^{\prime}=160, P_{u}$ is approximately $10 c^{\prime}$ or $2.3 q_{u}$ for the $\mathrm{z} / \mathrm{D}$ range from which data could be extracted with accuracy $(\mathrm{z} / \mathrm{D} \leq 1.5)$. Finite Element analyses of laterally loaded piles in a Tresca soil (e.g. Truong and Lehane 2014) suggest that likely upperbound $P_{u} / c^{\prime}$ or $P_{u} / q_{u}$ ratios at large $z / D$ values are about 15 and 3.5 respectively.

The foregoing analyses indicate that if a CPT has been performed at any given weak rock site and if $c^{\prime}$ and $\phi^{\prime}$ can be measured or estimated, the operational equivalent linear elastic modulus $\left(E_{s}\right)$ can be determined using Eq. [6] and the spherical cavity expansion solution of Yu and Houlsby (1991); an estimate of $E_{s}$ can also be made using Fig. 15a. A simple bi-linear approximation to the rock's $p-y$ characteristic, of the form indicated on Fig. 12 (but noting $p=P D$ ), can then be constructed with an initial (elastic) slope equal to $0.8 E_{s}$ extending to a maximum $p$ value $\left(p_{u}=P_{u} D\right)$ of approximately $0.06 \mathrm{q}_{\mathrm{c}} \mathrm{D}$ (as stated above, this multiple of $q_{c}$ may be conservative at large $z / D$ values). The lateral pile analysis can be performed using 
readily available commercial software with these $p-y$ characteristics and specification of the pile's flexural rigidity and yield moment capacities.

\section{Conclusions}

Instrumented lateral pile load tests in weak calcareous sandstone have shown that the lateral response of this material is not well predicted by either the weak rock model of Reese (1997) or the cemented soil model of Reese and Van Impe (2001). This paper shows that the lateral behavior of piles in weak rocks and cemented soils is better related directly to the CPT $q_{c}$ value with the equivalent elastic moduli of the rock controlling values of $q_{c}$ at the test site being very similar to those controlling lateral pile response. A simple bi-linear $p-y$ approximation of the lateral response is proposed requiring $q_{c}$ data and an estimate of the rock's effective stress strength parameters. It is shown that standard lateral pile analysis with such $p-y$ curves is likely to be sufficient for many practical purposes if the moment capacity of the pile section is incorporated in the analysis.

\section{Acknowledgements}

The authors gratefully acknowledge the on-site assistance provided by Tom Pine and Stuart Coutts from Belpile Pty Ltd. The research was funded by the Australian Research Council.

\section{References}

Abbs, A. F. 198). Lateral pile analysis in weak carbonate rocks. Geotechnical Practice in Offshore Engineering, Proc. Offshore technology conference, Austin, Texas, Paper OTC 4852, 546-556. 
Brinch Hansen, J. 1961. The ultimate resistance of rigid riles against transversal forces. Bulletin No. 12: Geoteknisk Institute, The Danish Geotechnical Institute.

BS EN 1992-1-1. 2004. Eurocode 2: Design of concrete structures - Part 1-1: General rules and rules for buildings: British Standards Institution. UK.

Carter, J.P., and Kulhawy, F.H. 1992. Analysis of laterally loaded shafts in rock. Journal of geotechnical engineering, ASCE, 118(6), 839-855.

Clark, A. R., and Walker, B. F. 1977. A proposed scheme for the classification and nomenclature for use in the engineering description of Middle Eastern sedimentary rocks. Géotechnique, 27(1), 93-99.

Doherty, J. 2014. User manual for LAP, Laterally loaded pile analysis. School of Civil, Environmental \& Mining Engineering, University of Western Australia, Perth WA 6009

Erbrich, C. T. 2004. A new method for the design of laterally loaded anchor piles in soft rock. Proc. Offshore technology conference, Houston, Texas, USA., Paper OTC 16441, 1-12.

Evans, L.T. and Duncan, J.M. 1982. Simplified analysis of laterally loaded piles (Vol. Report $\mathrm{UCB} / \mathrm{GT} / 82-04)$ : University of California at Berkley.

Goodman, R. E. 1989. Introduction to rock mechanics. $2^{\text {nd }}$ ed.,. New York, USA: John Wiley \& Sons.

Guo, F. 2015. Investigation of the lateral response of single piles in cemented sand and weak rock. PhD Thesis, The University of Western Australia, Perth, Australia. 
Lehane, B. M., Schneider, J. A., Lim, J. K., and Mortara, G. 2012. Shaft friction from instrumented displacement piles in an uncemented calcareous sand. Journal of Geotechnical and Geoenvironmental Engineering, ASCE, 138(11), 1357-1368.

Look, B. G. 2014. Handbook of geotechnical investigation and design tables. $2^{\text {nd }}$ Edition, CRC Press, ISBN 9781138001398.

Nyman, K.J. 1980. Field load tests of instrumented drilled shafts in coral limestone. Masters Thesis, University of Texas at Austin, USA.

Oasys. 2013. ADSEC computer manual (Version 8.2) (8.2 ed.). Central Square, Forth Street, Newcastle-Upon-Tyne, NE1 3PL, UK.: Oasys Limited.

Playford, P. E., Cockbain, A. E., and Low, G. H. 1976. The geology of the Perth Basin, Western Australia. Western Australia Geological Survey, Bulletin 124.

Poulos, H. G. 1971. Behavior of laterally loaded piles: I-single piles. Journal of the Soil Mechanics and foundations Division, ASCE, 97(5), 711-731.

Randolph, M. F., Dolwin, R., and Beck, R. 1994. Design of driven piles in sand. Géotechnique, 44(3), 427-448.

Reese, L.C. 1997. Analysis of laterally loaded piles in weak rock. Journal of Geotechnical and Geoenvironmental engineering, ASCE, 123(11), 1010-1017.

Reese, L.C., and Van Impe, W.F. 2001. Single piles and pile groups under lateral loading. A.A.Balkema, Rotterdam, Netherlands. 
Reese, L.C., Wang, S.T., and Vasquez, L. 2010. GROUP Version 8.0: A Program for the analysis of a group of piles subjected to vertical and lateral loading (Technical Manual). 3003 W. Howard Lane, Austin, Texas 78728: ENSOFT, INC.

Robertson, P. K. 2009. Interpretation of cone penetration tests - a unified approach. Canadian Geotechnical Journal, 46(11), 1337-1355.

Suryasentana, S. K., and Lehane, B. M. 2014. Numerical derivation of CPT-based p-y curves for piles in sand. Géotechnique, 64(3), 186-194.

Truong, P., and Lehane, B.M. 2014. Numerically derived CPT-based p-y curves for a soft clay modeled as an elastic perfectly plastic material. Proc. $3^{\text {rd }}$ International Symposium on Cone Penetration Testing, Paper \#3-25, Las Vegas, Nevada, USA.

Tomlinson M.J. and Woodward J. 2007. Pile design and construction practice. $5^{\text {th }}$ Edition CRC Press, ISBN 9780415385824.

Xu, X., and Lehane, B. M. 2008. Pile and penetrometer end bearing resistance in two-layered soil profiles. Géotechnique, 58(3), 187-197.

Yu, H. S., and Houlsby, G. T. 1991. Finite cavity expansion in dilatant soils: loading analysis. Géotechnique, 41(2), 173-183 


\section{Notation}

The following symbols are used in this paper:

$$
\begin{aligned}
& c^{\prime}=\text { effective cohesion; } \\
& D=\text { pile diameter; } \\
& e=\text { load eccentricity above ground level; } \\
& E_{s}=\text { Equivalent operational linear Young's modulus; } \\
& G_{o}=\text { small-strain shear modulus; } \\
& H=\text { lateral load applied at pile head; } \\
& I_{s, 50}=\text { Point load index (corrected to } 50 \mathrm{~mm} \text { diameter); } \\
& K_{c}=\text { Brinch-Hansen c' pressure coefficient; } \\
& K_{q}=\text { Brinch-Hansen vertical stress pressure coefficient; } \\
& M=\text { pile bending moment; } \\
& M_{y}=\text { yield moment of pile } \\
& P=\text { lateral pressure; } \\
& p=\text { lateral resistance per meter length; } \\
& p_{\text {lim }}=\text { limiting pressure of cavity expansion; } \\
& P_{u}=\text { ultimate soil/rock pressure; } \\
& q_{c}=\text { cone tip resistance; } \\
& q_{u}=\text { unconfined compressive strength; } \\
& t=\text { wall thickness of steel pipe; } \\
& V_{s}=\text { velocity of shear wave; } \\
& y=\text { lateral displacement of soil/pile; } \\
& z=\text { depth below ground surface; } \\
& \mathrm{A}=\text { strength reduction factor } \\
& \mathrm{y}_{\mathrm{h}}=\text { deflection of pile head; } \\
& \kappa=\text { pile curvature; } \\
& \mathrm{N}=\text { Poisson's ratio of soil or rock mass; } \\
& \sigma_{\mathrm{v}}^{\prime}=\text { effective overburden stress; and } \\
& \phi^{\prime}=\text { friction angle. }
\end{aligned}
$$


List of Figures

Figure 1 Typical view of stratified nature of Pinjar deposits

Figure 2 In-situ test data at Pinjar

Figure 3 Shear box test results on rock sample 'chunks' and reconstituted rock samples

Figure 4 (a) Deviator stress-axial strain data for block samples, (b) stress states at failure in triaxial tests compared with strength envelope from shear box tests

Figure 5 Experimental tests on drilled and grouted piles: (a) general view of lateral load test at Pinjar; (b) schematic showing test setup configuration (at stage of onsite pile calibration)

Figure 6 Lateral pile head load-displacement responses for test piles: (a) $340 \mathrm{~mm}$ piles; (b) $450 \mathrm{~mm}$ piles

Figure 7 Deflection profiles for $340 \mathrm{~mm}$ diameter piles at Pinjar

Figure 8 Measured and calculated moment-curvature relationships of test piles (at small and large curvatures)

Figure 9 Measured and interpolated bending moment profiles for 340mm diameter piles

Figure 10 Lateral pressure-displacement (P-y) curves derived for 340mm diameter piles

Figure 11 Comparison of maximum lateral pressures at Pinjar with existing predictive methods

Figure 12 Envelope of P-y curves with bi-linear approximations for the $340 \mathrm{~mm}$ diameter piles at Pinjar 
Figure 13 Normalized lateral load transfer curves curves at Pinjar compared with existing predictive methods

Figure 14 Comparison of calculated and measured pile head lateral load-displacement curves

Figure 15 Predicted relationship of $\mathrm{q}_{\mathrm{d}} / \mathrm{c}^{\prime}$ with (a) stiffness ratio $\mathrm{E}_{\mathrm{s}} / \mathrm{q}_{\mathrm{c}}$ and (b) $\mathrm{E}_{\mathrm{s}} / \mathrm{q}_{\mathrm{u}}$ 


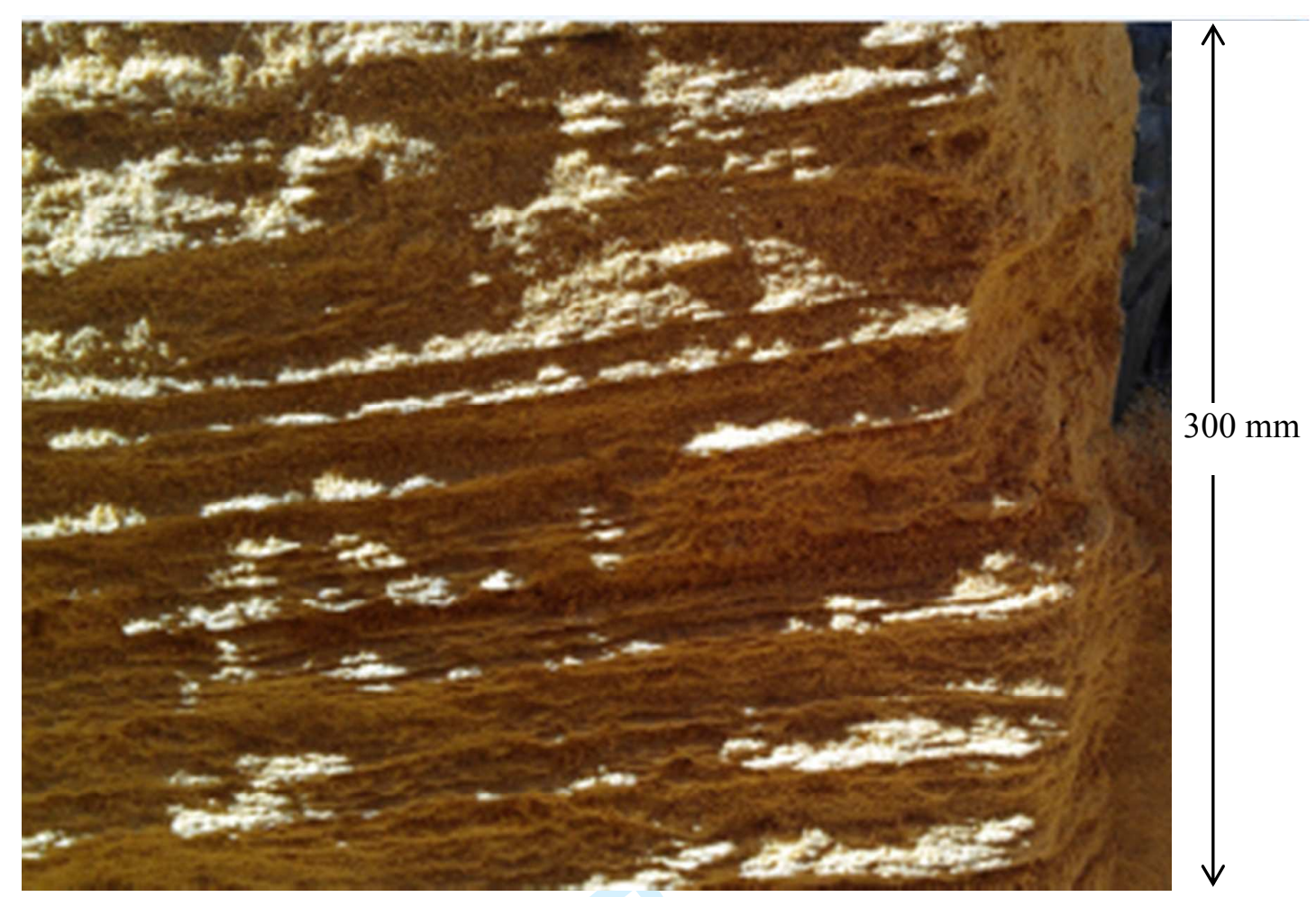

Figure 1 Typical view of stratified nature of Pinjar deposits 

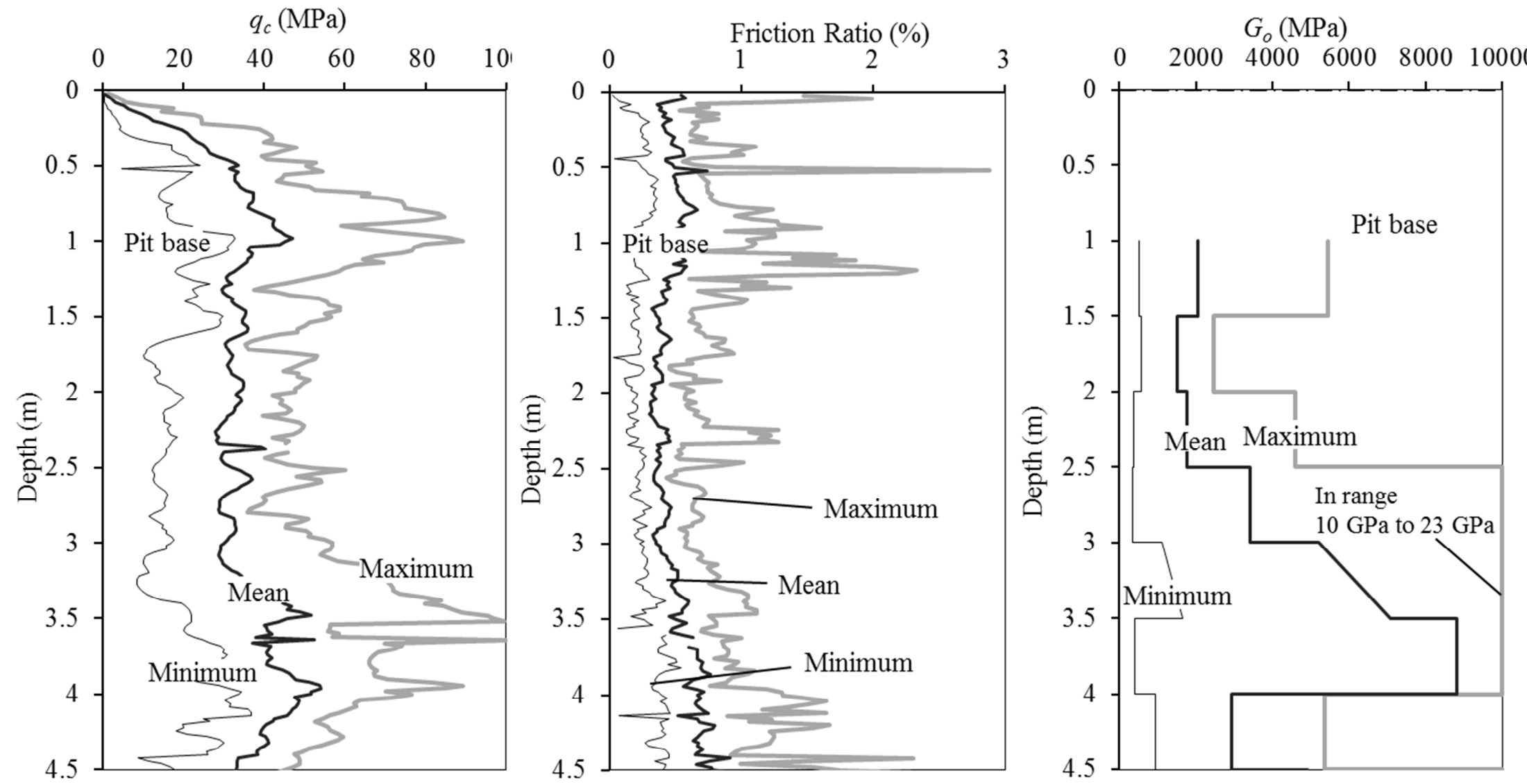

Figure 2 In-situ test data at Pinjar 


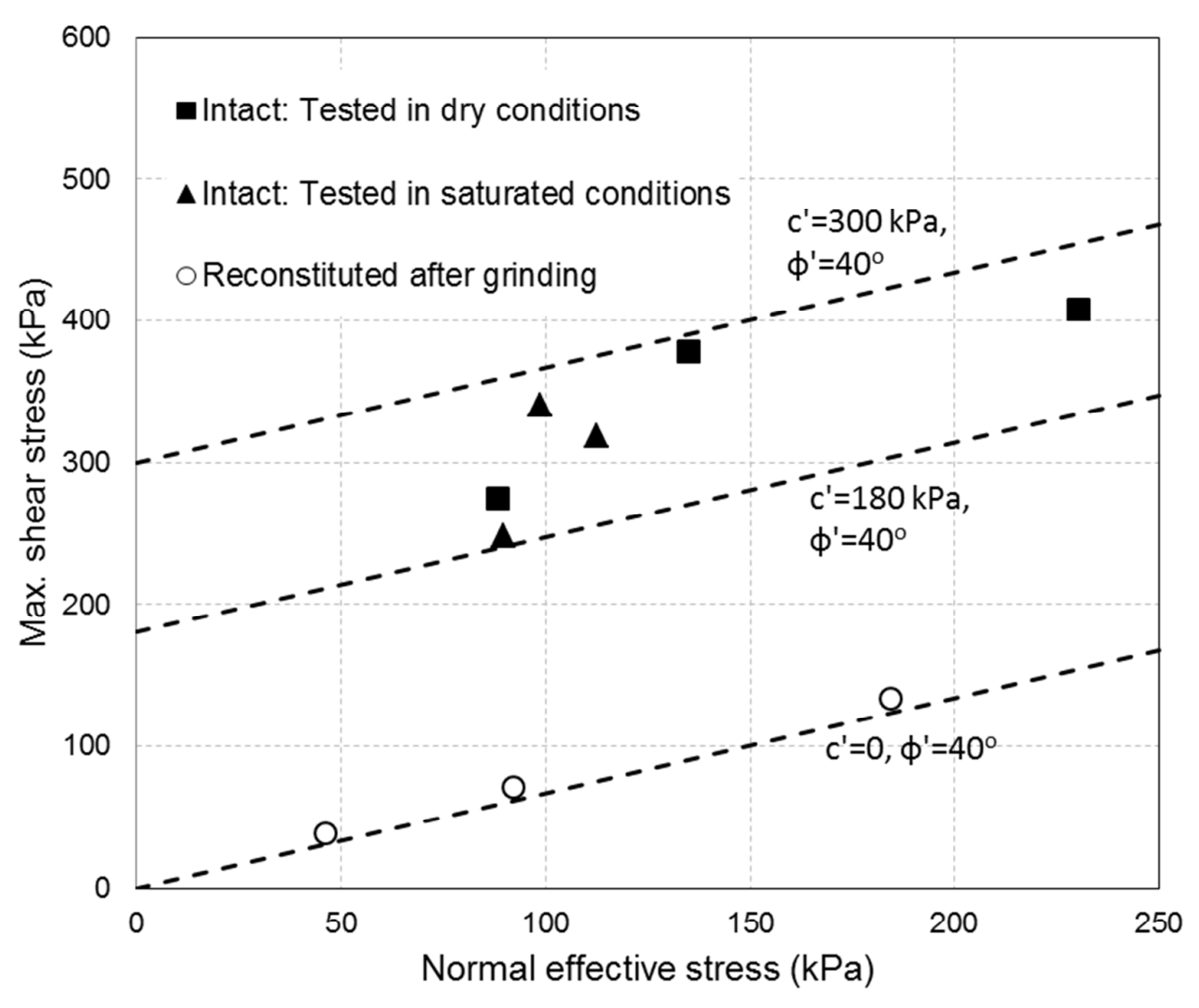

Figure 3 Shear box test results on rock sample 'chunks' and reconstituted rock samples 


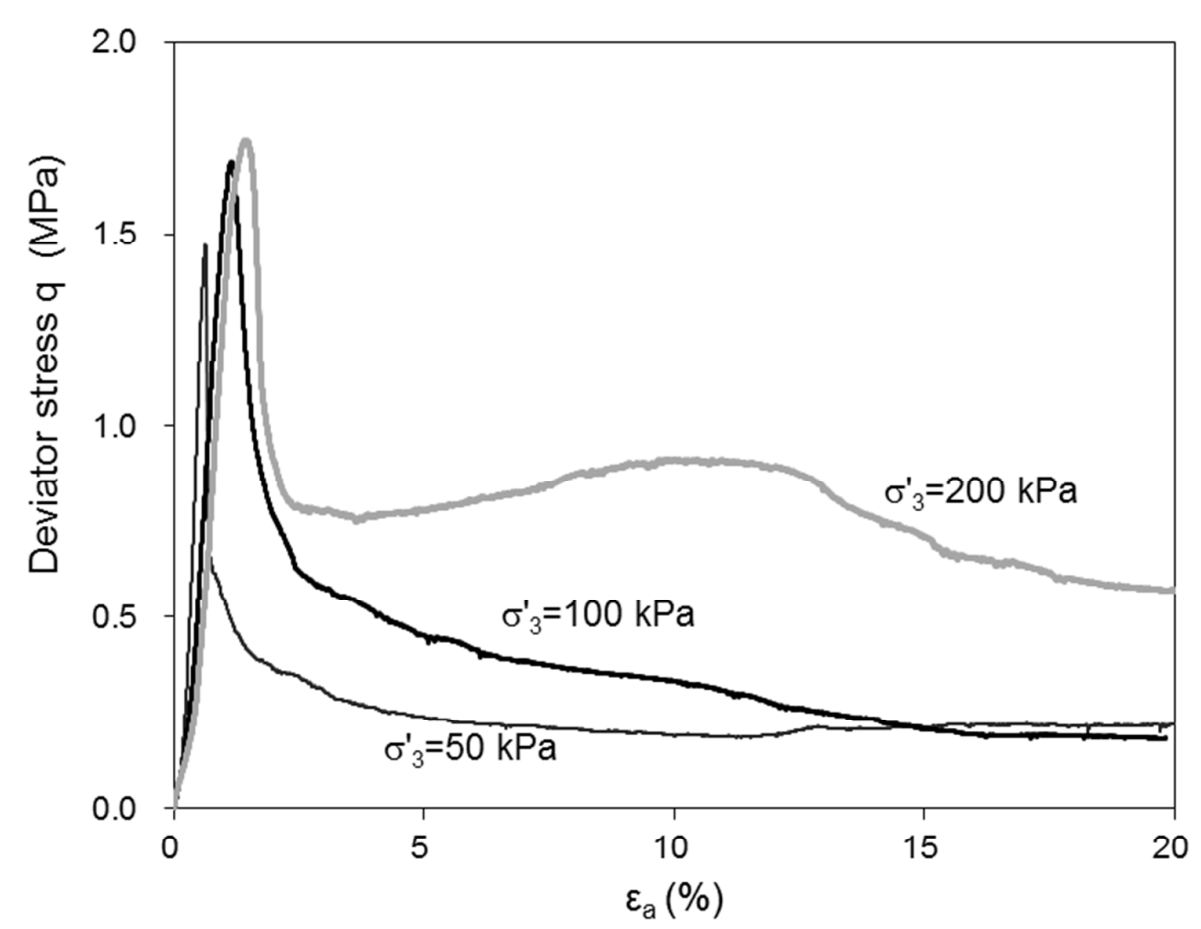

(a)

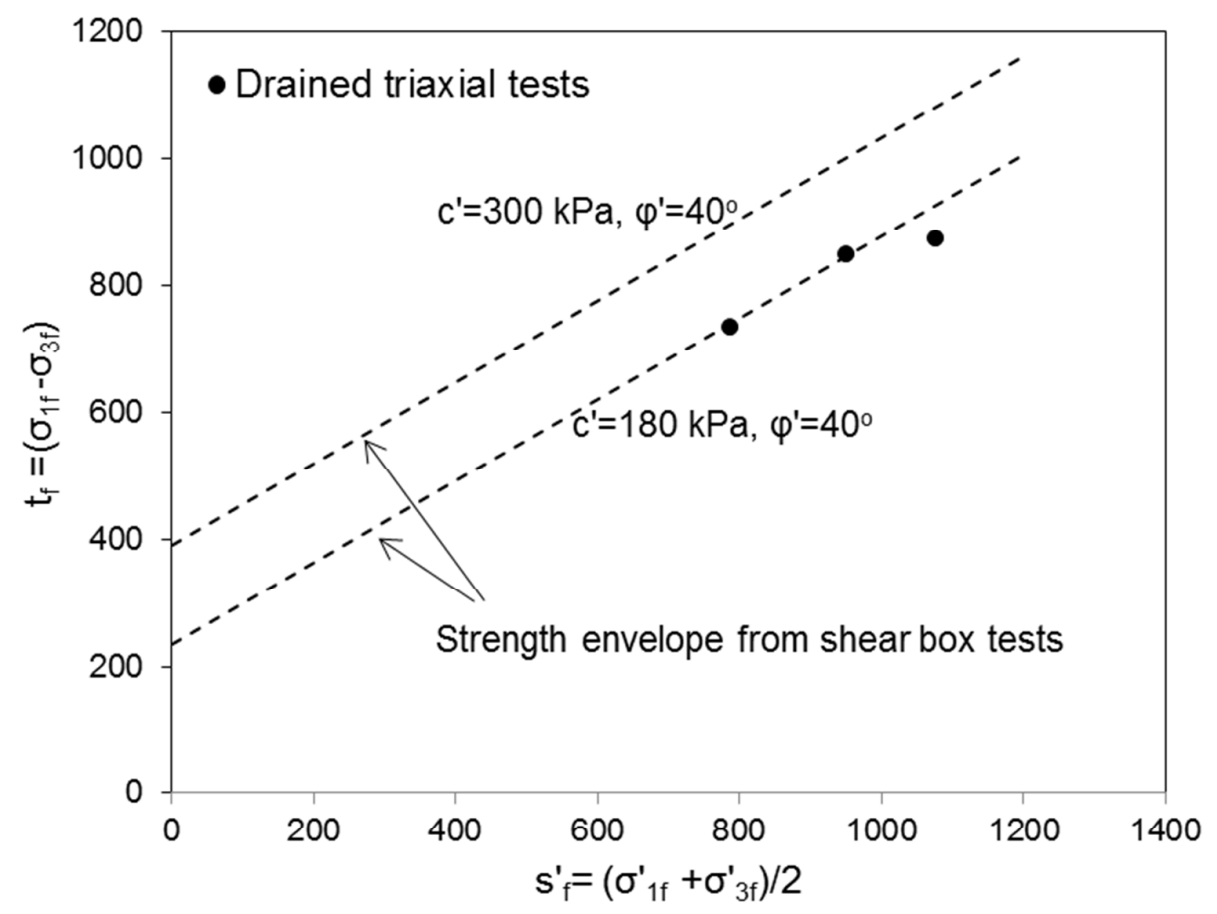

(b)

Figure 4 (a) Deviator stress-axial strain data for block samples, (b) stress states at failure in triaxial tests compared with strength envelope from shear box tests 


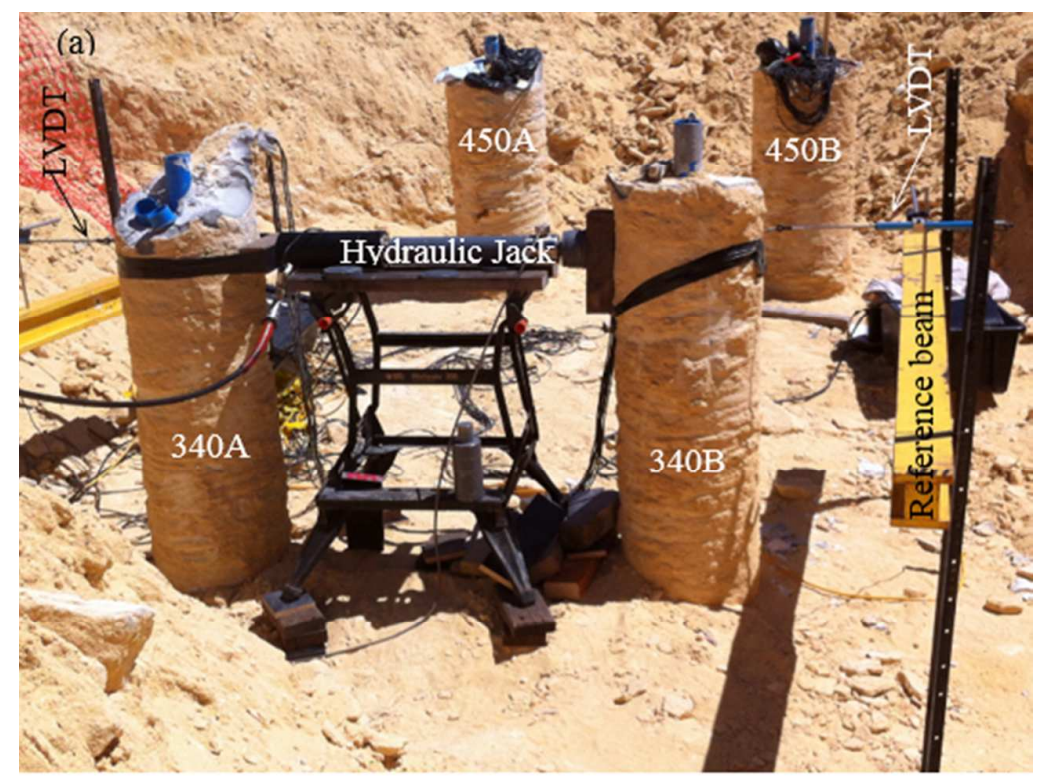

(b)

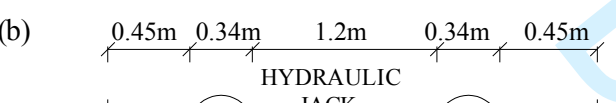
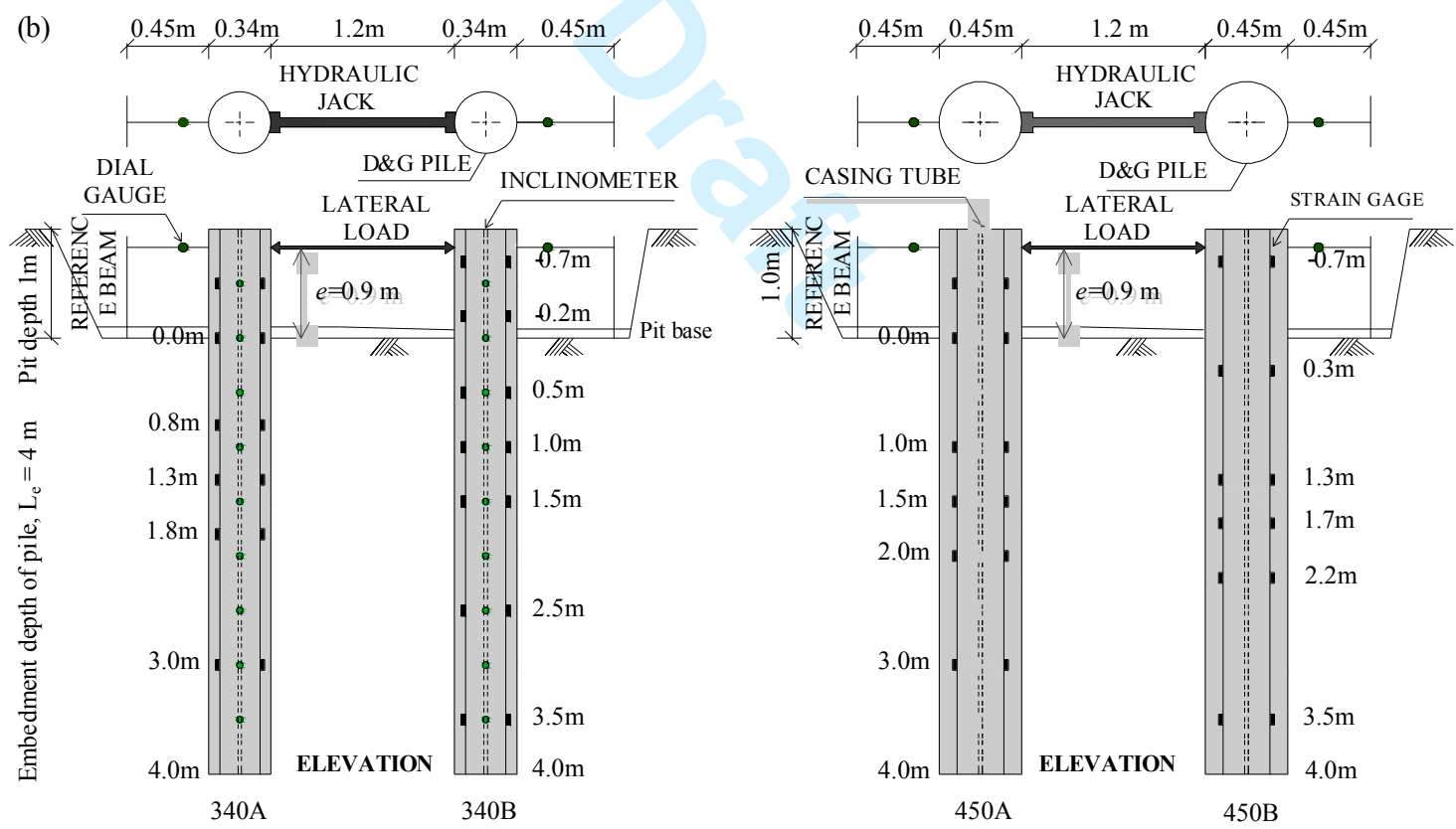

Figure 5 Experimental tests on drilled and grouted piles: (a) general view of lateral load test at Pinjar; (b) schematic showing test setup configuration (at stage of onsite pile calibration) 


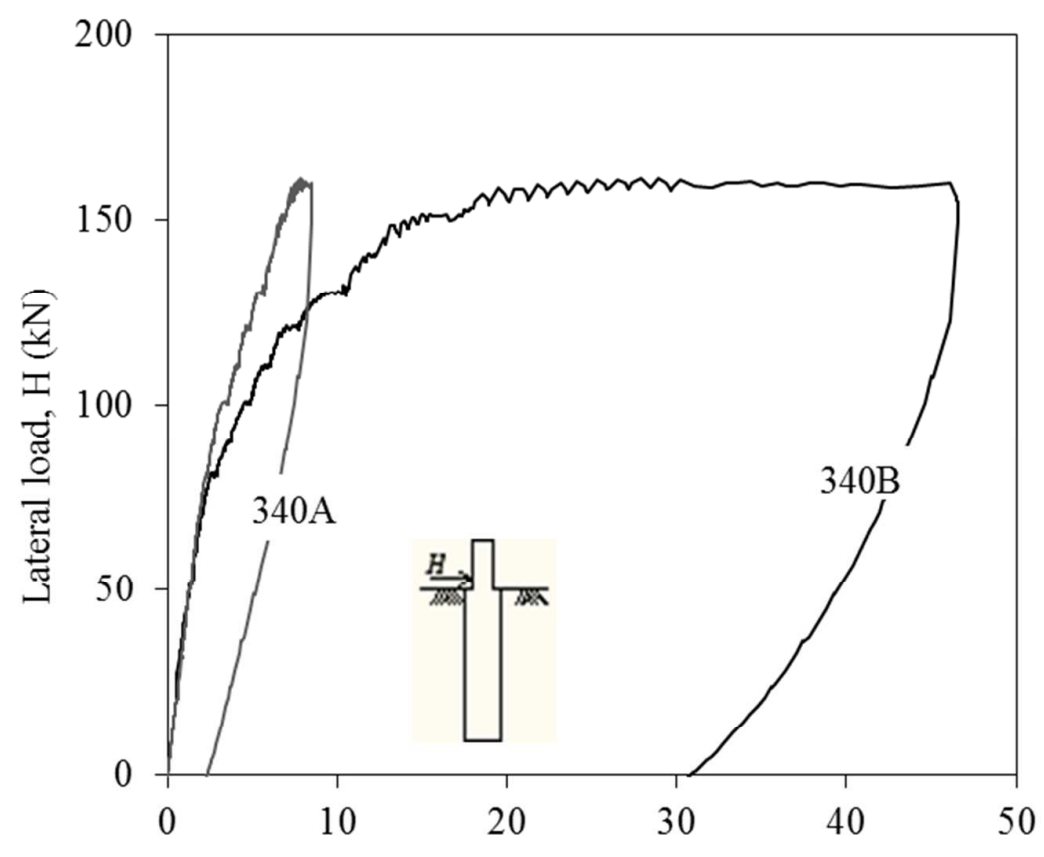

Pile head displacement at $e=0.32 \mathrm{~m}, \mathrm{y}_{\mathrm{h}}(\mathrm{mm})$

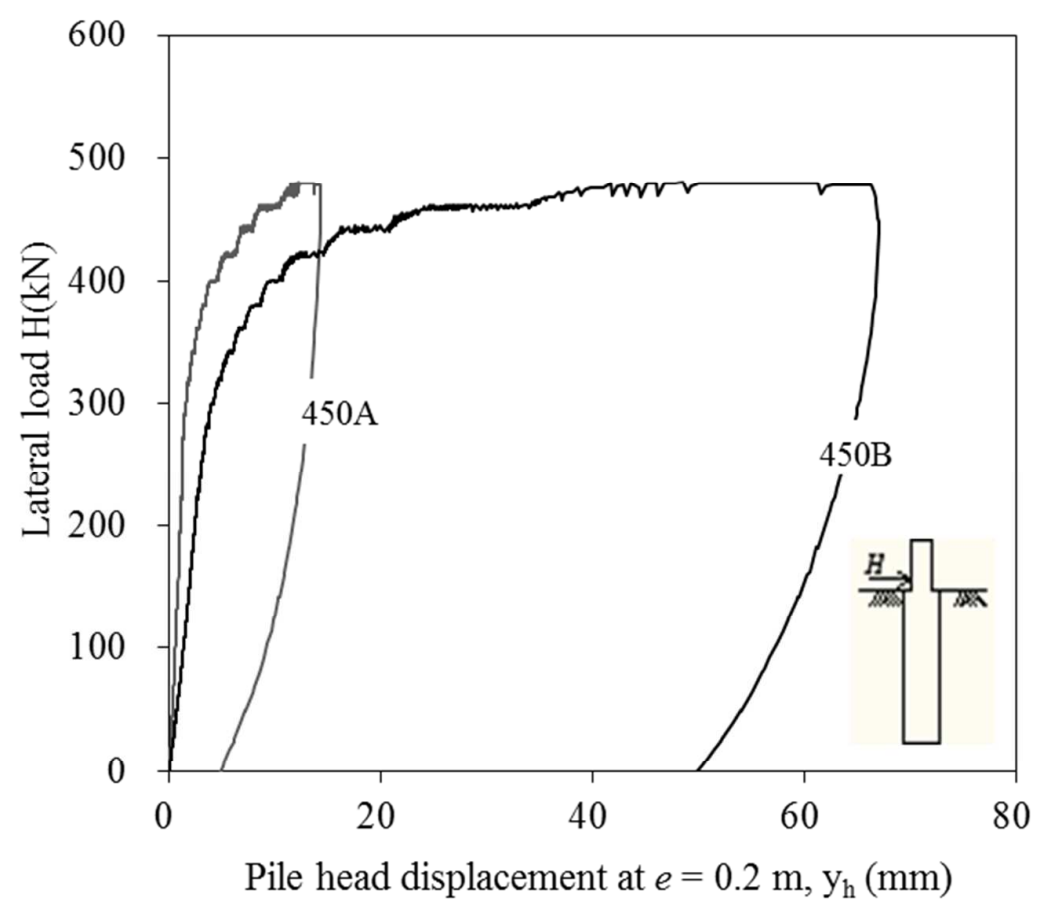

Figure 6 Lateral pile head load-displacement responses for test piles: (a) $340 \mathrm{~mm}$ piles;

(b) $450 \mathrm{~mm}$ piles 

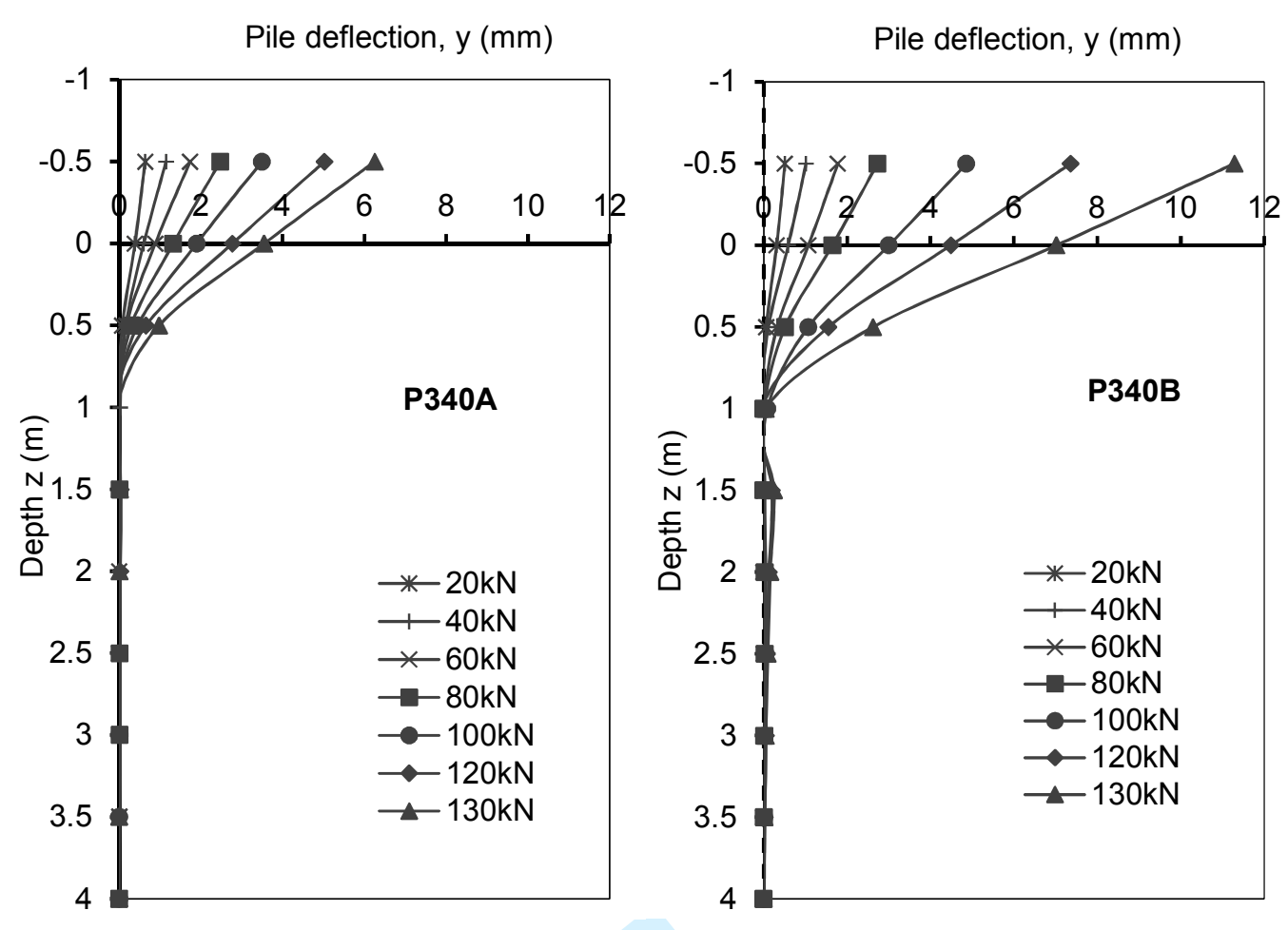

Figure 7 Deflection profiles for $340 \mathrm{~mm}$ diameter piles at Pinjar 

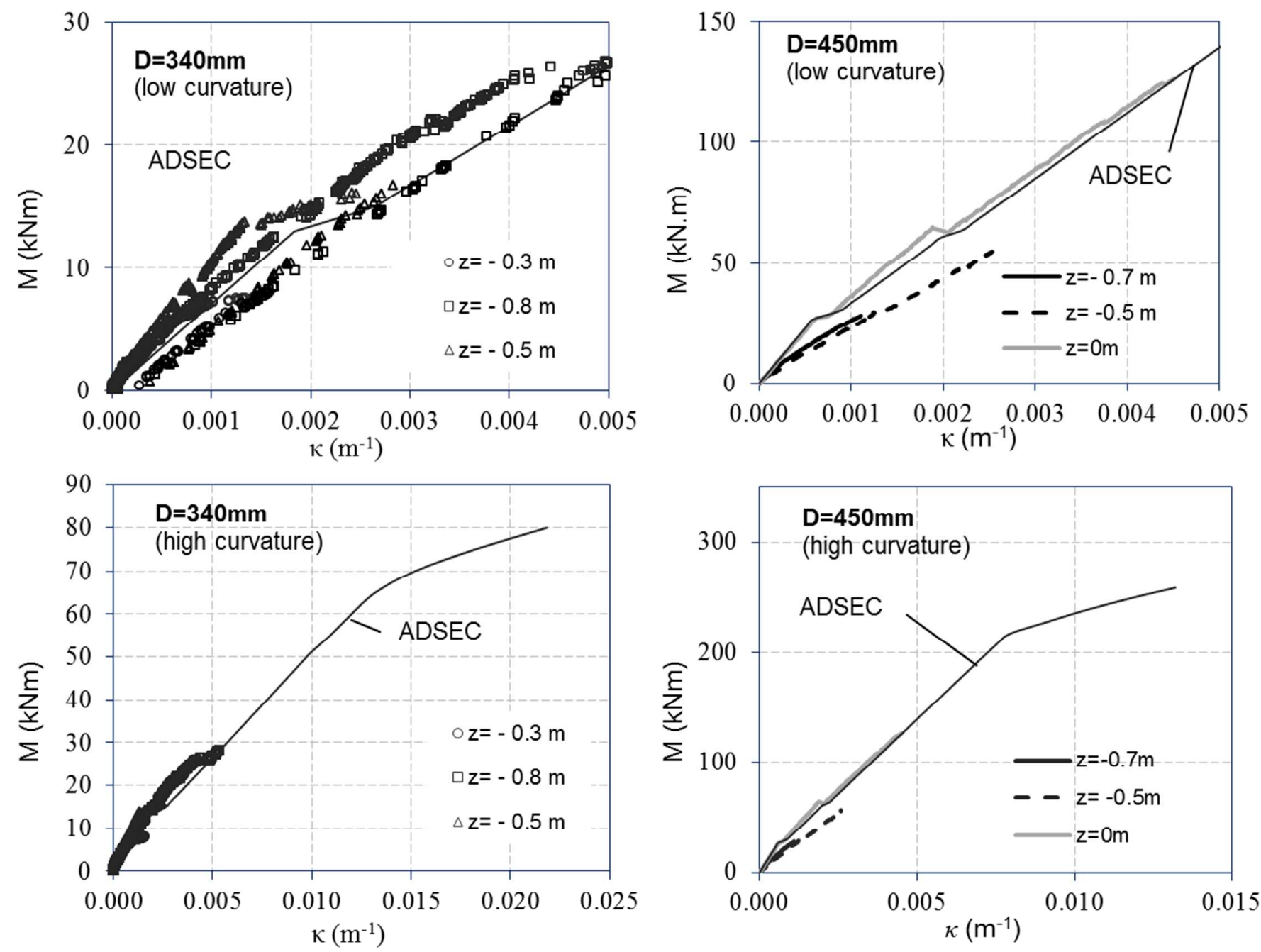

Figure $8 \quad$ Measured and calculated moment-curvature relationships of test piles (at small and large curvatures) 

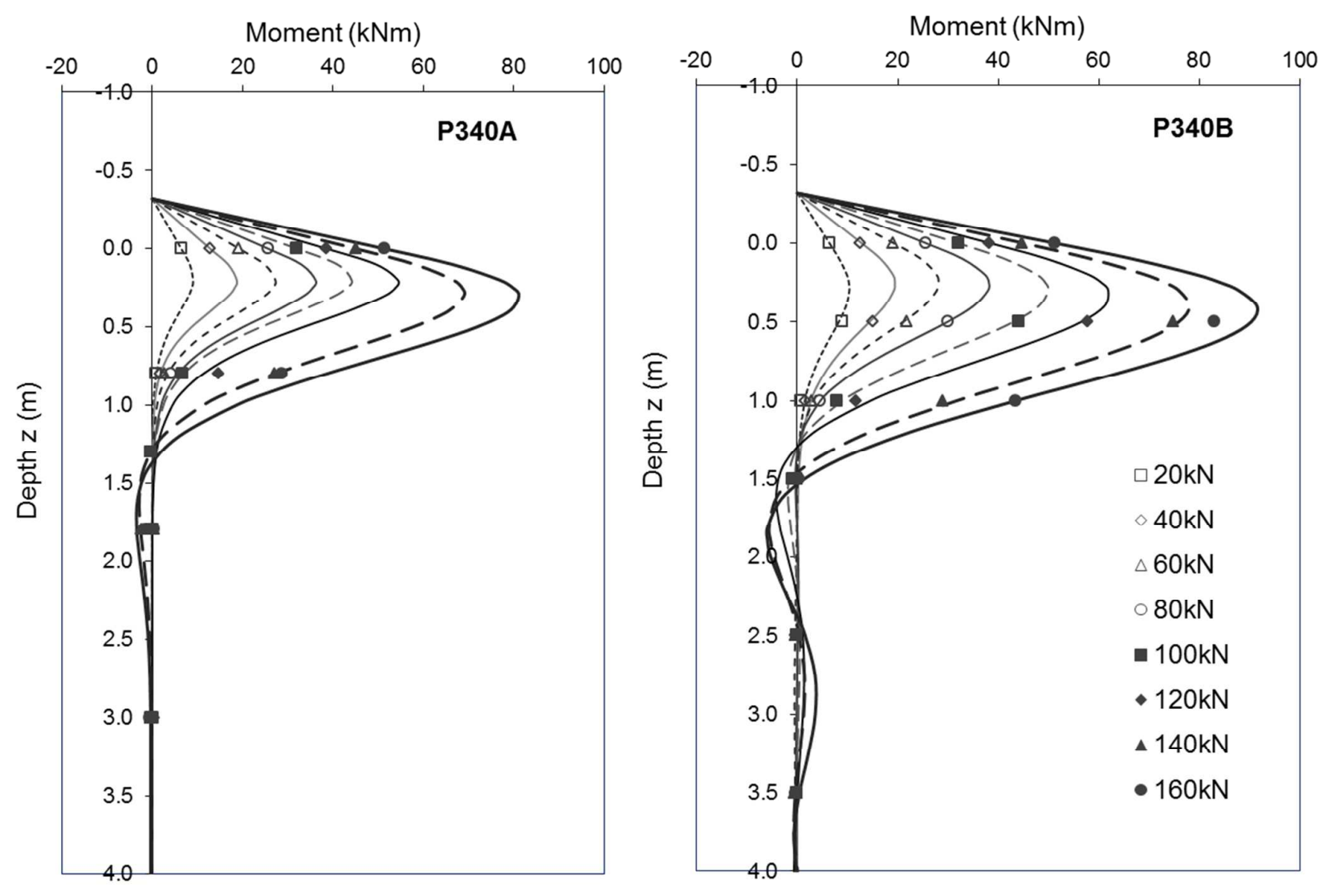

Figure 9 Measured and interpolated bending moment profiles for $340 \mathrm{~mm}$ diameter piles 

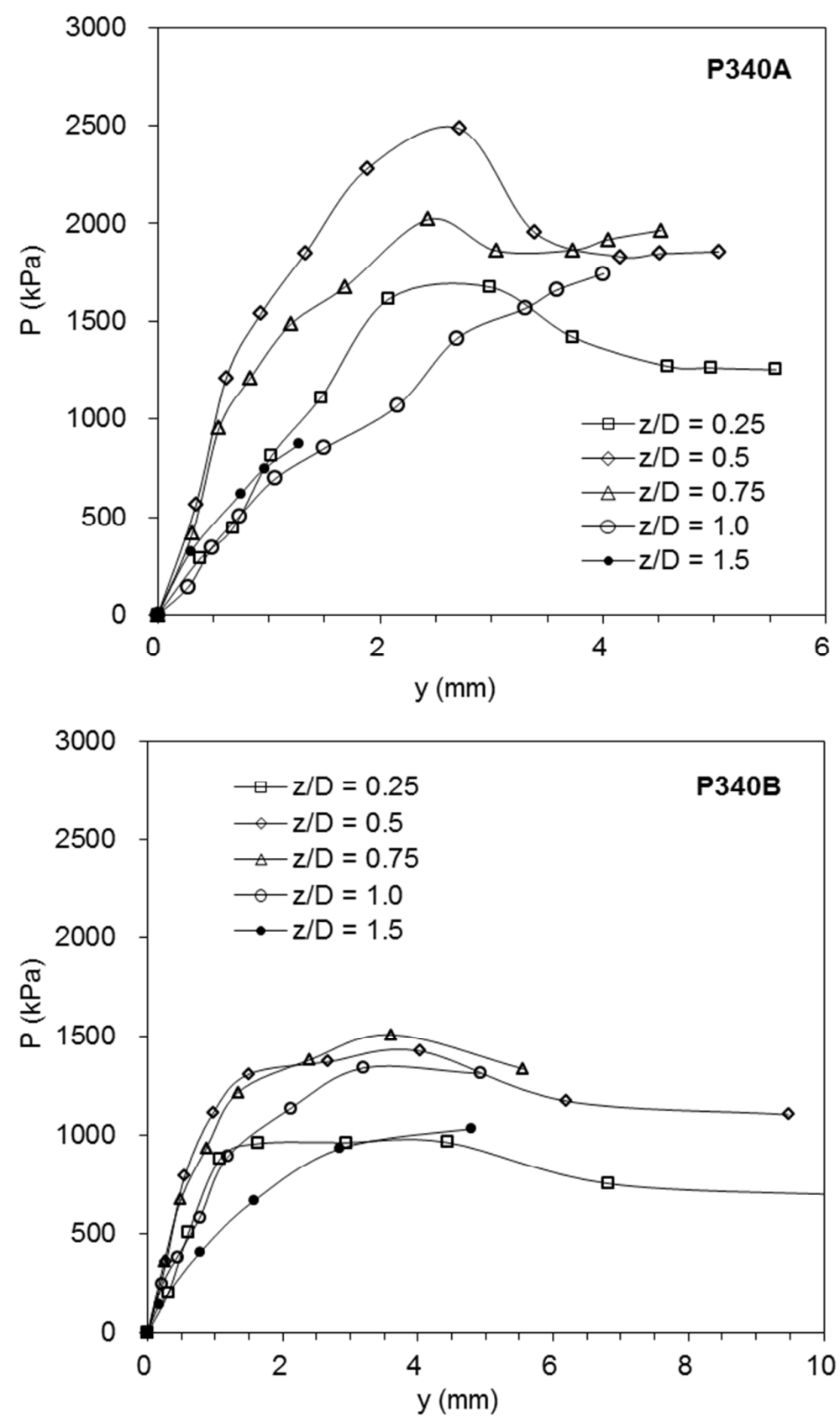

Figure 10 Lateral pressure-displacement (P-y) curves derived for 340mm diameter piles 


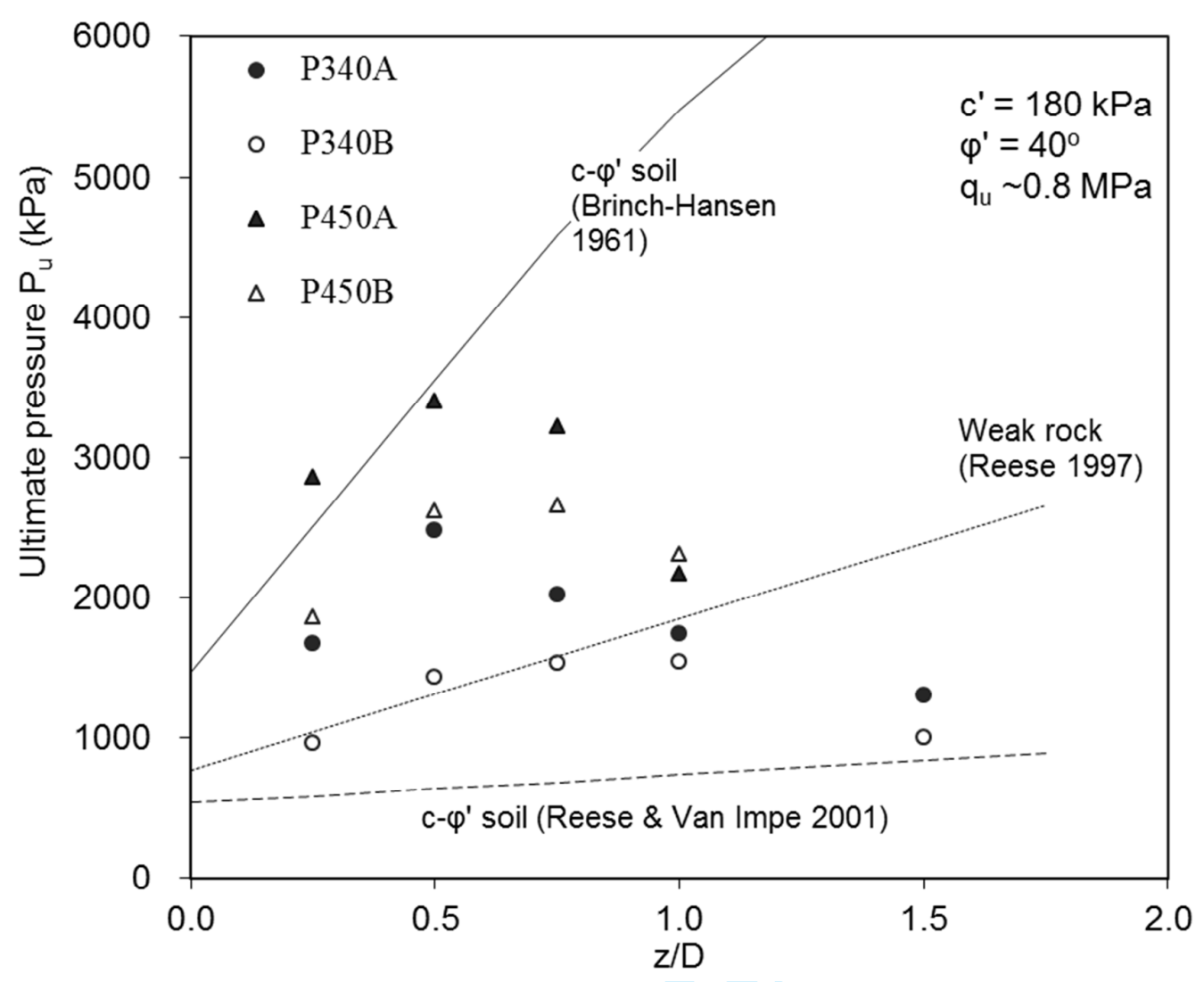

Figure 11 Comparison of maximum lateral pressures at Pinjar with existing predictive methods 


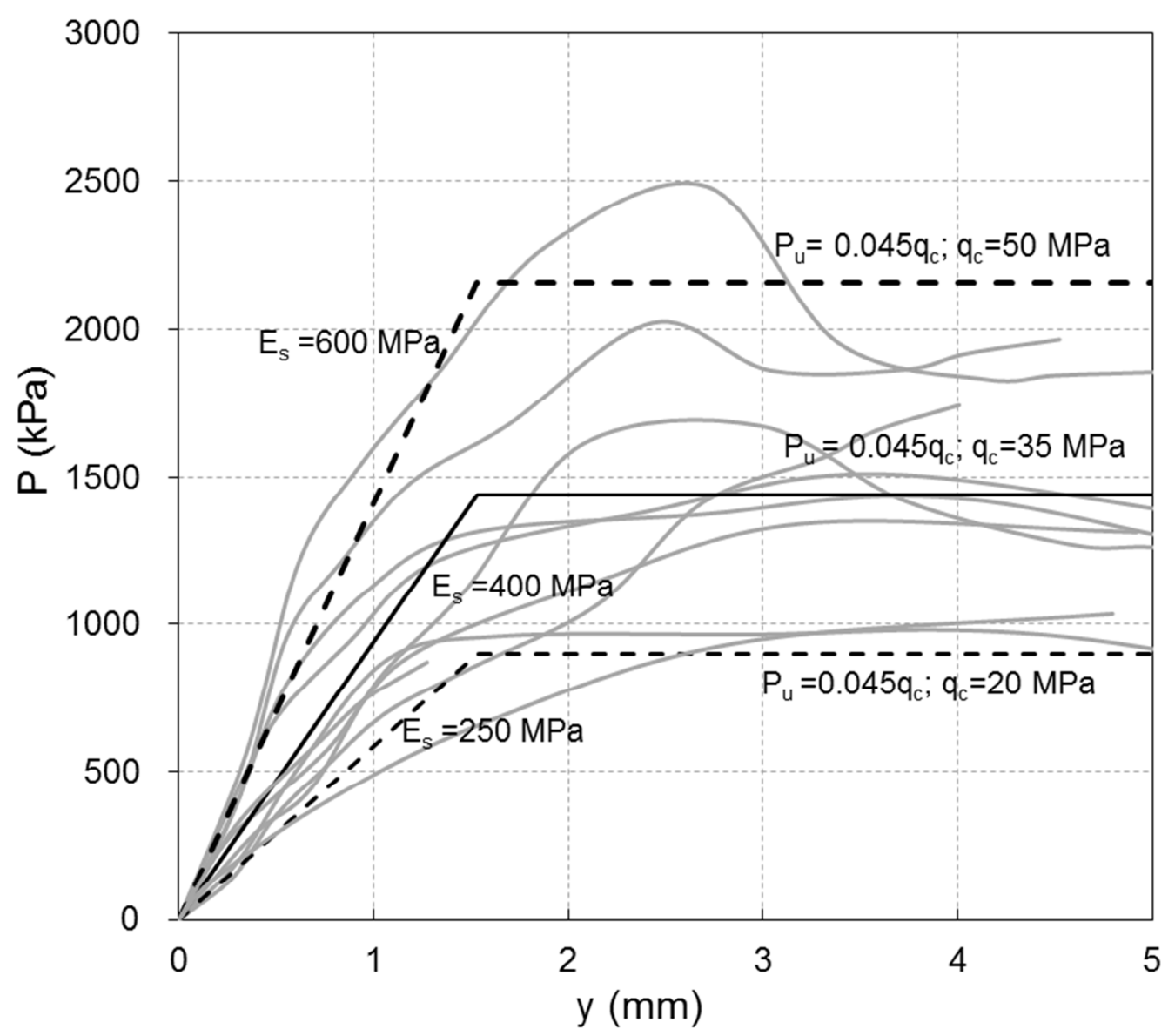

Figure 12 Envelope of P-y curves with bi-linear approximations for the $340 \mathrm{~mm}$ diameter piles at Pinjar 


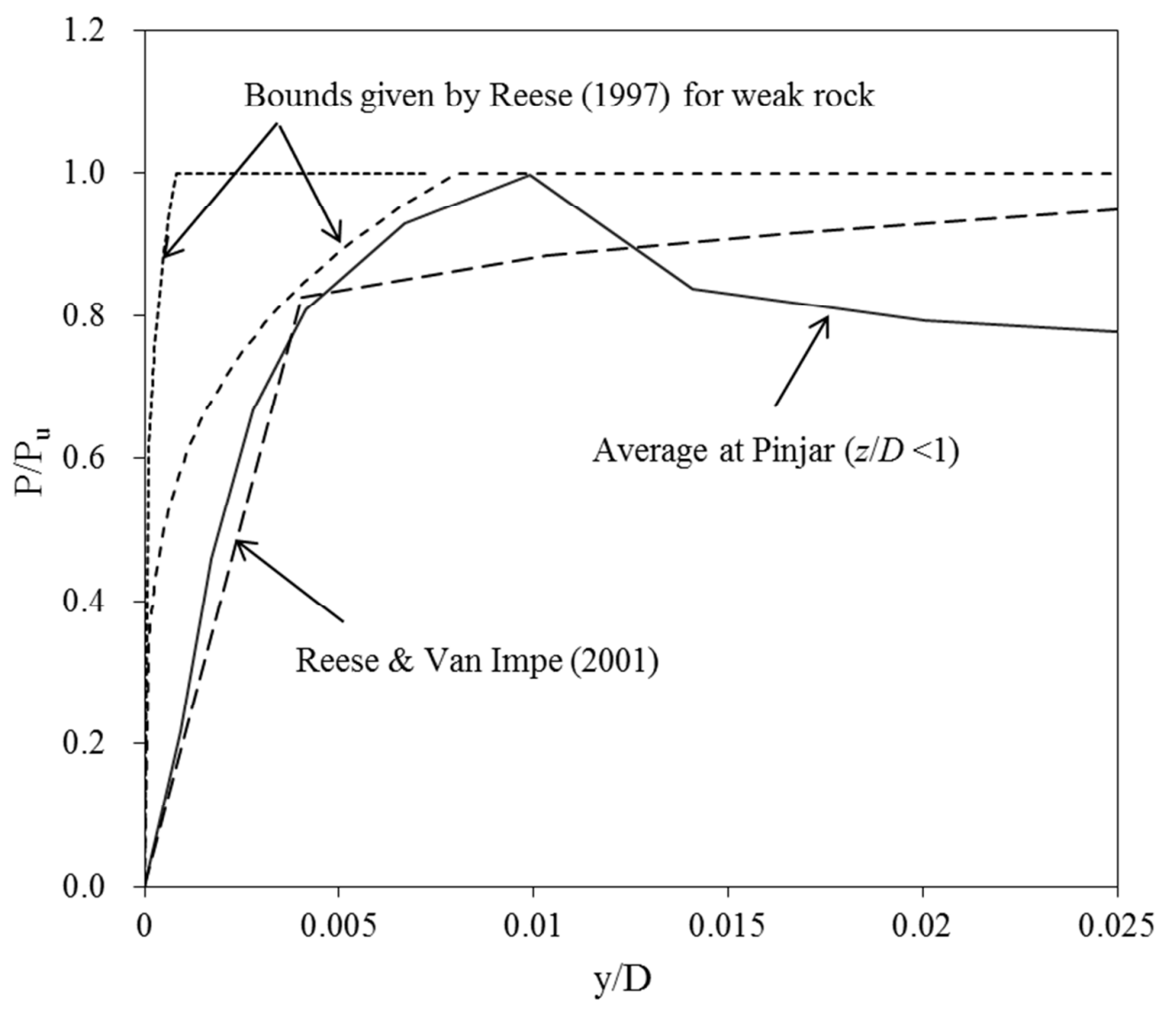

Figure 13 Normalized lateral load transfer curves at Pinjar compared with existing predictive methods 


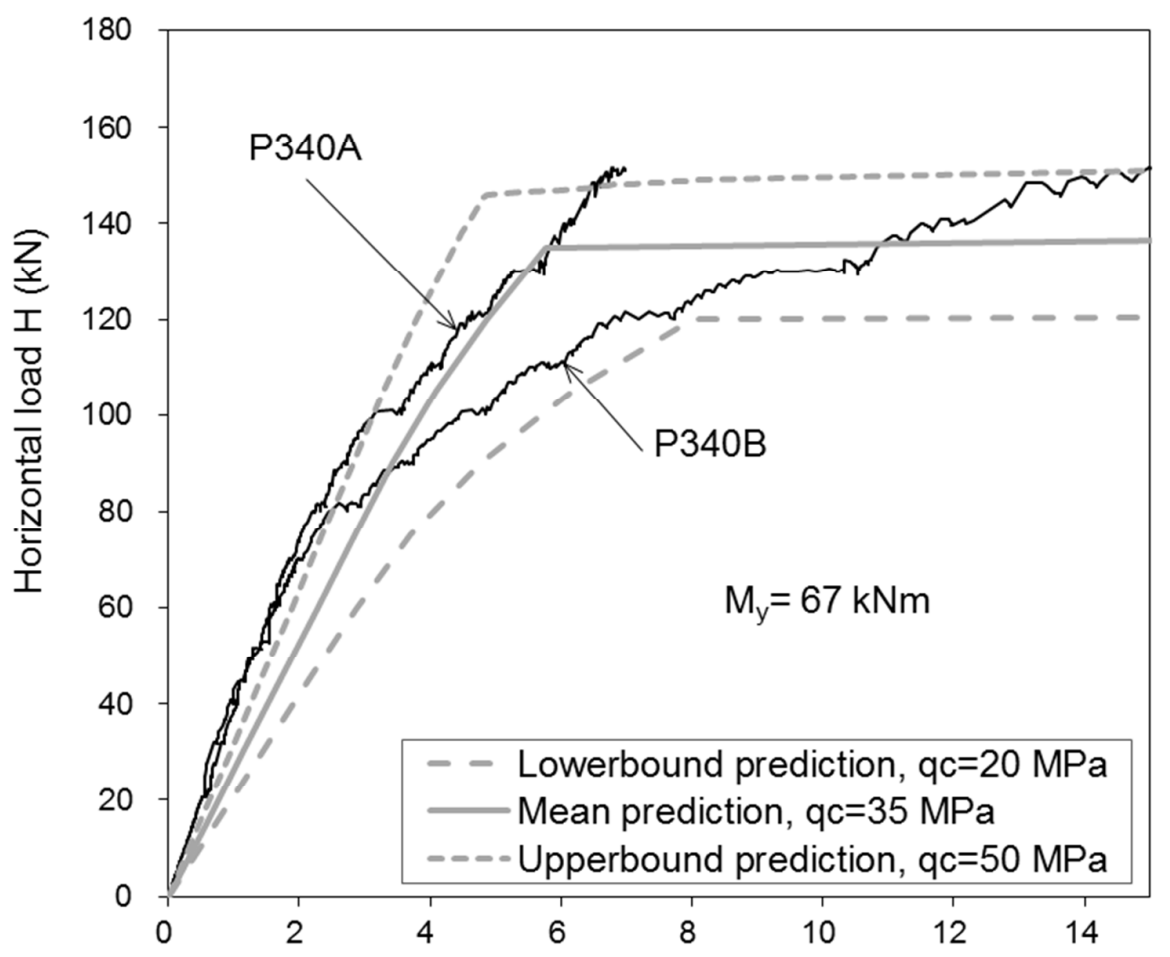

Pile head displacement $\mathrm{y}_{\mathrm{h}}(\mathrm{mm})$

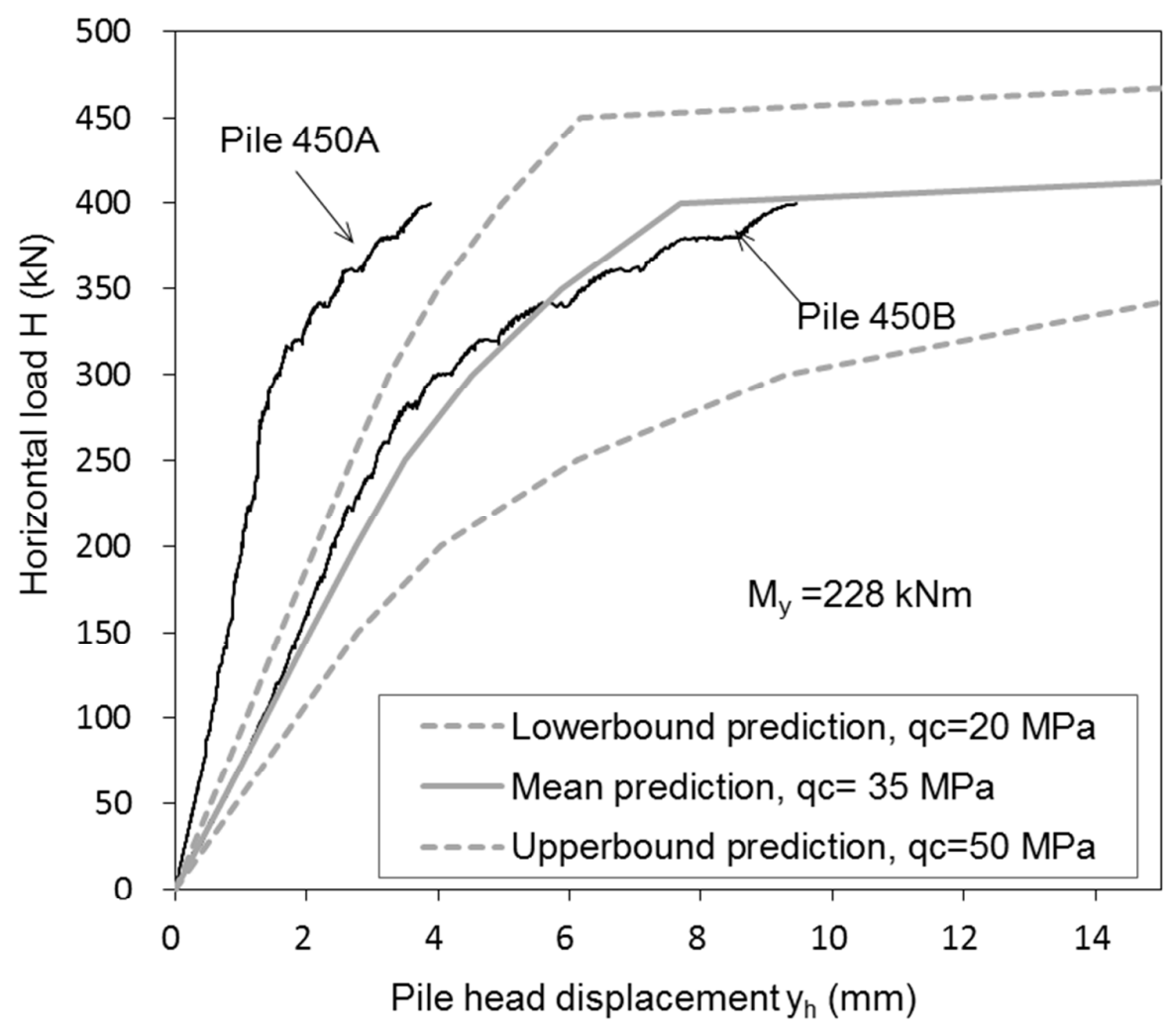

Figure 14 Comparison of calculated and measured pile head lateral load-displacement curves 


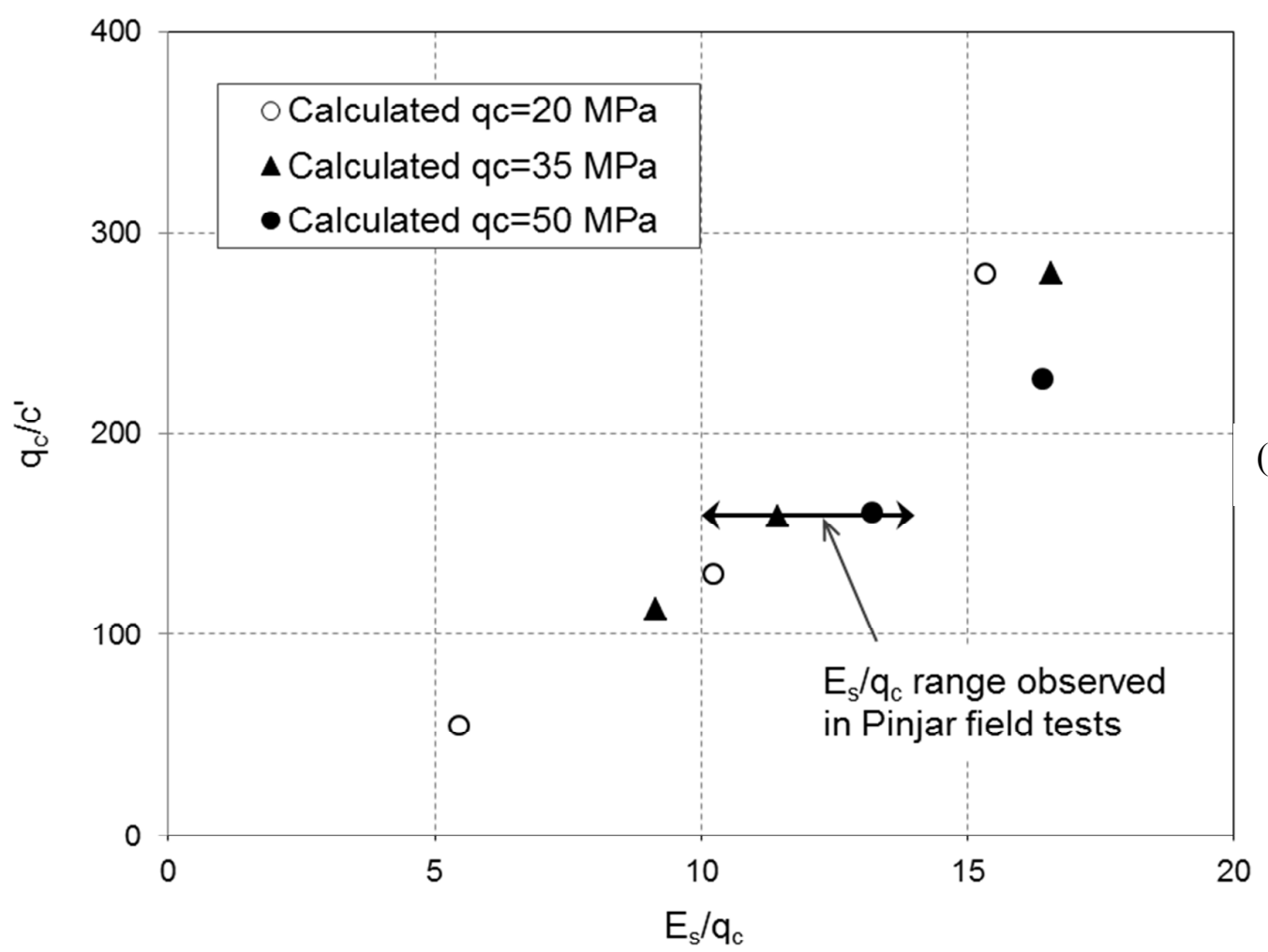

(a)

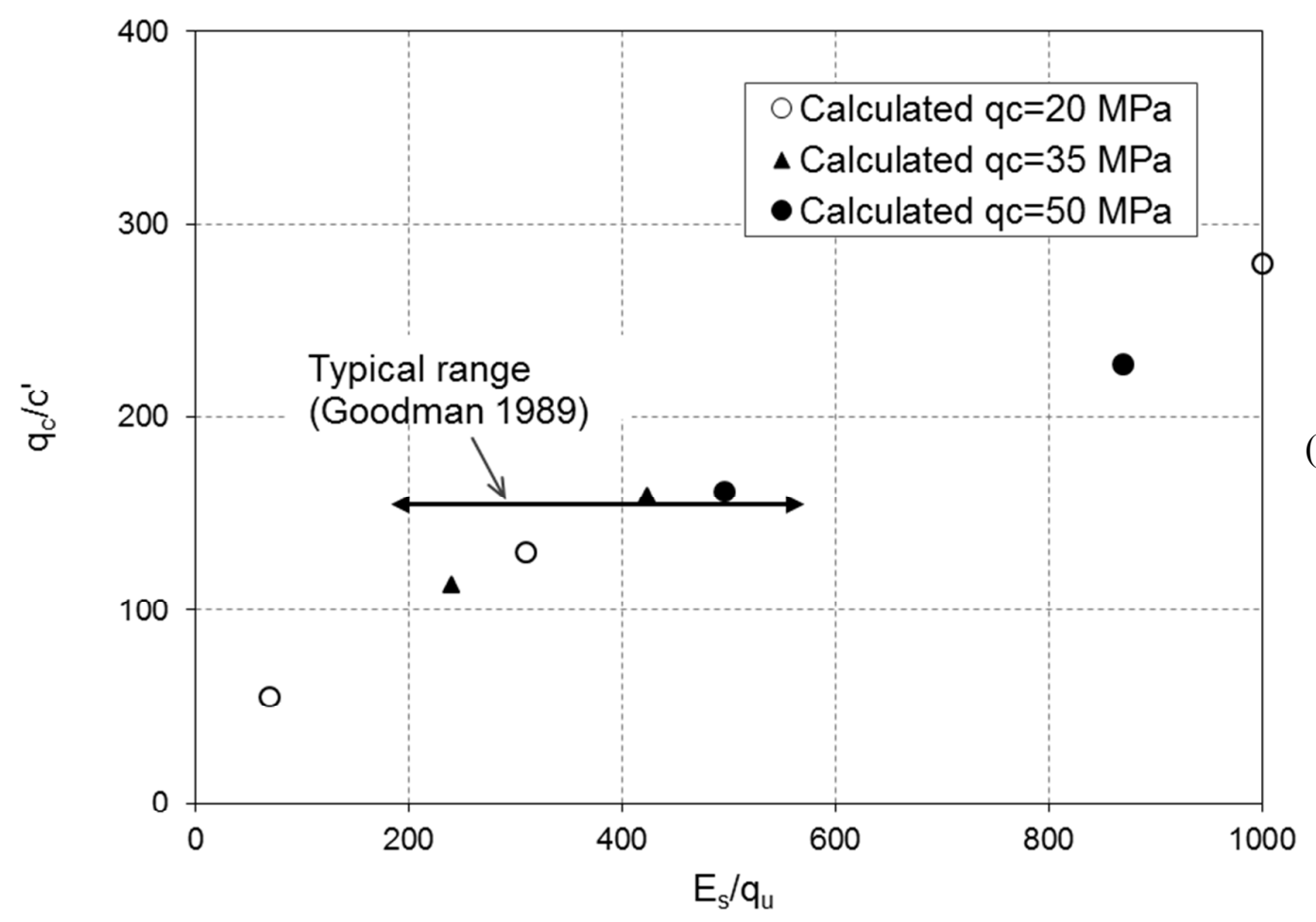

Figure 15 Predicted relationship of $\mathrm{q}_{\mathrm{c}} / \mathrm{c}^{\prime}$ with (a) stiffness ratio $\mathrm{E}_{\mathrm{s}} / \mathrm{q}_{\mathrm{c}}$ and (b) $\mathrm{E}_{\mathrm{s}} / \mathrm{q}_{\mathrm{u}}$ 
Table 1. Test pile summary

\begin{tabular}{|c|c|c|c|c|c|c|c|c|c|}
\hline \multirow[t]{2}{*}{ Pile Nos. } & $\begin{array}{l}\text { External } \\
\text { pile } \\
\text { diameter }\end{array}$ & $\begin{array}{l}\text { Steel pipe } \\
\text { diameter }\end{array}$ & $\begin{array}{l}\text { Pipe } \\
\text { Wall } \\
\text { thickness }\end{array}$ & $\begin{array}{c}\text { Eccentricity } \\
\text { of lateral } \\
\text { load }\end{array}$ & $\mathrm{E}_{\text {grout }}{ }^{*}$ & $\begin{array}{l}\text { Tensile \& Comp. } \\
\text { strength* }\end{array}$ & $\begin{array}{l}\text { Flexural rigidity (prior to } \\
\text { cracking of external } \\
\text { annulus) }\end{array}$ & $\begin{array}{l}\text { Moment } \\
\text { at first } \\
\text { yield }\end{array}$ & $\begin{array}{l}\text { Plastic } \\
\text { capacity }\end{array}$ \\
\hline & $D(\mathrm{~mm})$ & $(\mathrm{mm})$ & $t(\mathrm{~mm})$ & $e(\mathrm{~m})$ & $(\mathrm{GPa})$ & $(\mathrm{MPa})$ & $\mathrm{kNm}^{2}$ & $M y(\mathrm{kNm})$ & $M_{\mathrm{p}}(\mathrm{kNm})$ \\
\hline P340A \& P340B & 340 & 219 & 4.8 & 0.32 & 4 & $1.5 \& 12$ & 7200 & 67 & 90 \\
\hline P450A \& P450B & 450 & 356 & 6.4 & 0.2 & 4 & $1.5 \& 12$ & 31750 & 228 & 300 \\
\hline
\end{tabular}

* Backfigured from on-site calibration test 